\title{
Recent progress in nanocomposites based on conducting polymer: application as electrochemical sensors
}

\author{
Mama El Rhazi ${ }^{1}$ - Sanaa Majid ${ }^{1,2} \cdot$ Miloud Elbasri $^{1} \cdot$ Fatima Ezzahra Salih $^{1} \cdot$ Larbi Oularbi $^{1} \cdot$ Khalid Lafdi $^{3}$
}

Received: 1 March 2018 / Accepted: 26 May 2018 / Published online: 1 June 2018

(c) The Author(s) 2018

\begin{abstract}
Over the years, intensive research works have been devoted to conducting polymers due to their potential application in many fields such as fuel cell, sensors, and capacitors. To improve the properties of these compounds, several new approaches have been developed which consist in combining conducting polymers and nanoparticles. Then, this review intends to give a clear overview on nanocomposites based on conducting polymers, synthesis, characterization, and their application as electrochemical sensors. For this, the paper is divided into two parts: the first part will highlight the nanocomposites synthesized by combination of carbon nanomaterials (CNMs) and conducting polymers. The preparation of polymer/CNMs such as graphene and carbon nanotube modified electrode is presented coupled with relevant applications. The second part consists of a review of nanocomposites synthesized by combination of metal nanoparticles and conducting polymers.
\end{abstract}

Keywords Conducting polymers $\cdot$ Carbon nanomaterials $\cdot$ Metal nanoparticles $\cdot$ Nanocomposites

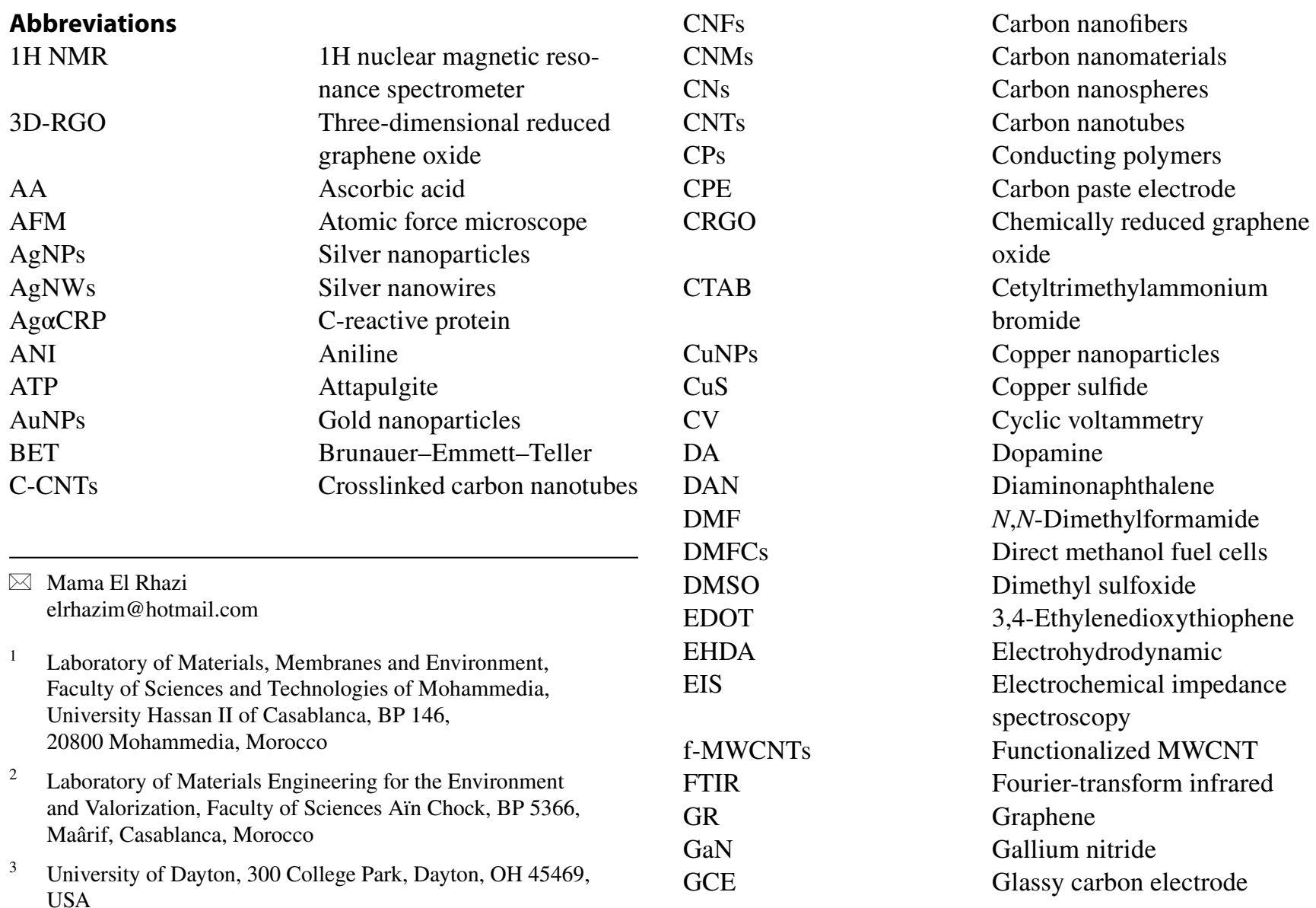




GO
ITO
LOD
LOQ
MIP
MIPM
$\mathrm{MnO}_{2}$-NPs
MNPs
MoS

\section{MWCNT}

MWNTsg-PtBMA- $b$-PS

NiPs
NPs
$p$-AHNSA
PANI
PdNPs
PEDOT

PEDOT:PSS

PNPAg
Poly(DTCPA-co-BHTBT)

PPy
PPyox
PS
PS- $b$-PtBMA
PSS
PTh
PtNPs
PVA
PVP
RGO
RGO-g-PANI

SDBS

SEBS
Graphene oxide

Indium tin oxide

Limit of detection

Limit of quantification

Molecularly imprinted

polymer

Molecularly imprinted poly-

mer membranes

Manganesedioxide

nanoparticles

Metal nanoparticles

Molybdenum disulfide

nanosheets

Multi-walled carbon

nanotubes

Multiwall carbon nanotube

graft polystyrene-block-

poly(tert-butyl methacrylate)

Nickel ion particles

Nanoparticles

Poly4-amino-3-hydroxy-

1-naphthalene sulfonic acid

Polyaniline

Palladium nanoparticles

Poly (3,4-ethylenedioxythiophene)

Poly(3,4-ethylenedioxythiophene)-polystyrene sulfonic acid

Nanocomposite blend

Poly ((2,5-dithie-

nyl-3,4-(1,8-naphthalene)

cyclopentadienone)-co-

4,7-bis(3-hexylthiophen-2-yl)

benzo [c] $[1,2,5]$ thiadiazole

Polypyrrole

Overoxidized polypyrrole

Polystyrene

Polystyrene-block-poly(tert-

butyl methacrylate)

Poly(sodium

4-styrenesulfonate)

Polythiophene

Platinum nanoparticles

Polyvinyl alcohol

Polyvinylpyrrolydone

Reduced graphene oxide

Polyaniline grafted reduced

graphene oxide

Sodium dodecylbenzene

sulfonate

Poly(styrene- $b$-(ethylene- $c o$ -

butylene)- $b$-styrene)

\begin{tabular}{|c|c|}
\hline SEM & $\begin{array}{l}\text { Scanning electron } \\
\text { microscopy }\end{array}$ \\
\hline SMZ & Herbicide simazine \\
\hline SWCNT & $\begin{array}{l}\text { Single-walled carbon } \\
\text { nanotubes }\end{array}$ \\
\hline SWV & Square wave voltammetry \\
\hline TEM & $\begin{array}{l}\text { Transmission electron } \\
\text { microscopy }\end{array}$ \\
\hline TGA & Thermal gravimetric analysis \\
\hline XPS & $\begin{array}{l}\text { X-ray photoelectron } \\
\text { spectroscopy }\end{array}$ \\
\hline YADH & Alcohol dehydrogenase \\
\hline
\end{tabular}

\section{Introduction}

Organic conducting polymers, born in 1977 with the pioneering work of MacDiarmid, have received great attention due to their potential application $[1,2]$. Intensive research works have been devoted to preparation and characterization of conducting polymers such as polyaniline (PANI), polypyrrole (PPy), diaminonaphthalene (DAN), and their derivatives. Their application in batteries, sensors, capacitors, electronic devices, or electrochromic displays was very promising [3-5]. Carbon nanomaterials (CNMs) including fullerenes, single-walled carbon nanotubes (SWCNT), multiwalled carbon nanotubes (MWCNT), carbon nanofibers (CNFs), carbon nanospheres (CNs), graphene, and graphene oxide (GO) are novel materials of the twenty-first century [6] because of their large surface area, good environmental stability [7], exceptional electrical, thermal, chemical, and mechanical properties [8]. Due to these properties, CNMs had found a great interest in fields of composite materials and energy conversion [9], sensors [10], medicine [11], emission devices [12], and nanoscale electronic components [13].

Many efforts have been made to combine CNMs and polymers to produce functional nanocomposite materials with superior properties for fundamental and technological perspectives [10]. The conducting polymers such as polyaniline (PANI), polypyrrole (PPy), polythiophene (PTh), and poly(3,4-ethylenedioxythiophene) (PEDOT) have been explored as matrices to incorporate a number of CNMs such as: fullerenes [14], single and multi-walled carbon nanotubes (CNTs) $[15,16]$, carbon nanofibers (CNFs) $[17,18]$, carbon nanospheres (CNs) $[19,20]$, graphene, and graphene oxide [21-23]. The incorporation of carbon nanomaterials in polymer matrices is a very attractive way to combine the mechanical and electrical properties [24]. These new nanocomposites open up new opportunities, ranging from sensors [25-27], electrochemical capacitor [28, 29], solar cells [30], transistors [31], to molecular electronic devices [22], etc. More recently, nanocomposite 
based on CPs, and metal nanoparticles (MNPs) such as gold, platinum, palladium, and silver with different compositions and dimensions have been intensively investigated [32-36]. The incorporation of metal nanoparticles in polymers matrices would to a host nanocomposite with additional physical properties [37-39]. Several approaches have been described and employed to synthesize metal or metal oxide nanoparticle-conducting polymers nanocomposites [34, 38, 40]. Different approaches using electrochemical methods involving incorporation of metal nanoparticles during the electrosynthesis of the polymer, electrodeposition of metal nanoparticles on the preformed polymer electrodes, reduction of metal salts dissolved in a polymer matrix or incorporation of preformed nanoparticles during polymerization of monomers have been reported. Chemical preparation [41], sonochemical method [42], sol-gel technique [43], ultrasonic irradiation [44], and photochemical preparation [45] have also been used. Nanocomposites based on conducting polymers and nanoparticles (CNMs or MNPs) were the focus of increasing numbers of papers or reviews to understand fundamental aspects and the potential applications of these nanostructures [46]. According to the sciences direct web site, the number of paper devoted to nanocomposites based CP and NPs increased from 3427 in 2011 to 7444 in July 2017, as shown in Fig. 1, indicating the importance of nanomaterial composites.

The present review analyzes the recent progresses in the synthesis of nanocomposites based on conducting polymers and carbon nanomaterials and/or metal nanoparticles during the last years and their applications in the field of electrochemical sensors. It should be noted that only conducting polymers with conjugated- $\pi$-bond will be considered in this review.

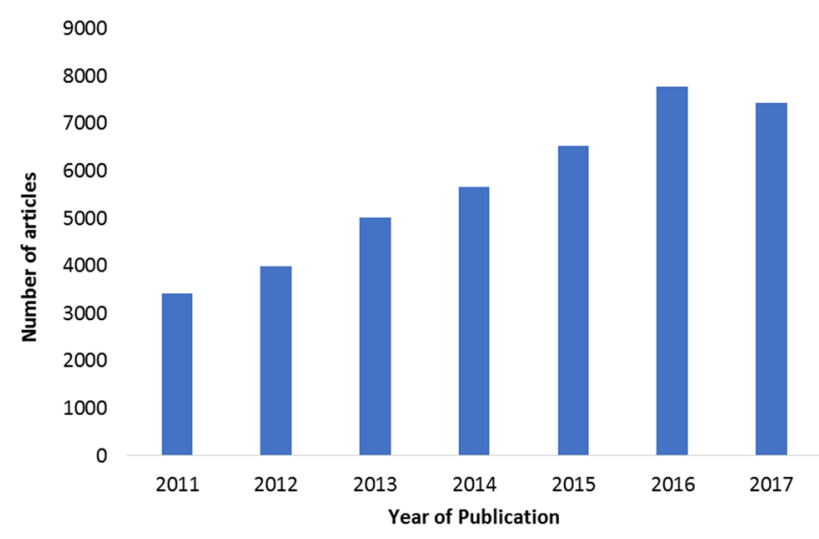

Fig. 1 Histogram representing the numbers of scientific articles published per year during the last 6 years (research performed on 10 July 2017 with "Science Direct", with CP and NPs)

\section{Nanocomposites synthesized by combination of carbon nanomaterials and conducting polymers}

Combination of conducting polymer matrix and carbon nanomaterials (CNMs) such as graphene, carbon nanofibers (CNFs), and carbon nanotubes (CNTs) to form polymer nanocomposites plays a very promising role due to their better structural and functional properties such as high aspect ratio, high mechanical strength, and high electrical properties [24, 47, 48]. In the last decade, large progress was made, resulting in the opening of new possibilities in the use of these properties for a variety of applications. The overall performances of CNMs/polymer nanocomposites are largely governed by the dispersion of CNM in the polymer matrix. Therefore, a homogeneous dispersion of $\mathrm{CNM}$ is an important issue in the preparation of CNM/ polymer nanocomposites [17, 22, 49-51]. Up to date, a large number of reviews have been reported on composites of conducting polymers and CNMs for application in supercapacitors and chemical sensors [52-54]. Carbon nanotubes and graphene are considered as the most innovative CNMs who are attracting enormous interest for their use in sensors [52] and their potential application as energy storage materials [55]. The most commonly used conducting polymers are polyaniline (PANI), polypyrrole (PPy), and poly[3,4-ethylenedioxythiophene] (PEDOT) [56-58]. Several methods for synthesis of nanocomposites have been reported in the literature. $\mathrm{CNM}$ /polymer nanocomposites can be synthesized by electrochemical or chemical processing. Chemical method is the common processing that can be performed either by solution mixing or by in situ chemical polymerization. Solution mixing is the method in which CNMs and polymer are mixed with a suitable solvent, and then, the nanocomposites are formed after the evaporation of the solvent in a controlled condition. It was demonstrated that this method enables to dropcast films with up to $60 \mathrm{wt} \%$ CNT content, although can result in reagglomeration of the CNTs during the casting/ evaporation process [52]. In situ chemical polymerization achieved by oxidation of corresponding monomers using an oxidizing agent. The main advantage of this method is that it produces polymer grafted CNMs, mixed with free polymer chains. Moreover, due to the small size of monomeric molecules, the homogeneity of the resulting composite adducts is much higher than mixing CNTs and polymer chains in solution [59]. However, it cannot achieve the same level of homogeneity and integrity in its polymerized product as can be produced by electrochemical polymerization [56]. The electrochemical polymerization takes only some minutes instead of some hours in case of chemical polymerization. Polymers can be formed by 
electrochemical deposition on electrodes modified with CNMs which leads to the better dispersion and interactions between CNMs and polymer. Better uniformity can be obtained by the electrochemically co-deposited composites from a solution containing monomers and dispersed CNMs leading to the most homogeneous network structure. Figure 2 shows the schematic illustration of the process of fabricating $\mathrm{CNM}$ /polymer nanocomposites with traditional chemical methods.

(a) Nanocomposites were prepared by in situ chemical polymerization involving monomer and carbon nanomaterials with different weight ratios after being sonicated to obtain homogenous mixture [60, 61].

(b) In mixing method, the commercial polymers were dissolved in suitable organic solvents, mixed and sonicated. Mangu et al. used $N, N$-dimethylformamide (DMF), dimethyl sulfoxide (DMSO) to dissolve PEDOT:PSS in the volume ratio of 3:1 and 2-propanol, ethylene glycol, DMSO, and DMF to dissolve PANI [62]. Then, carbon nanomaterials were added to this solution and sonicated. These nanocomposites obtained in solution form can be casted on suitable substrate or precipitated by filtration before being dried.

Electrochemical methods are investigated to prepare $\mathrm{CNM}$ /polymer nanocomposites and are summarized in Fig. 3. Two methods are generally used:

(a) The modified electrode was prepared by dropping of the well-dispersed carbon nanomaterials on the surface of the electrode substrate. Conducting polymers were electropolymerized using cyclic voltammetry in the presence of monomer dissolved in a solution generally in acidic medium $[63,64]$. A typical example in Fig. 4 was obtained in our laboratory using this method and concern polymerization of 1,5-diaminonaphthalene with CNFs [65].

(b) Electrochemical co-deposition was performed in aqueous solution containing monomer and carbon nanomaterials, using potentiostatic, galvanostatic, or cyclic voltammetry $(\mathrm{CV})$. The solution was stirred and ultrasonicated before polymerization. After electropolymerization, the modified electrode was washed thoroughly with water and dried at room temperature [66-68].

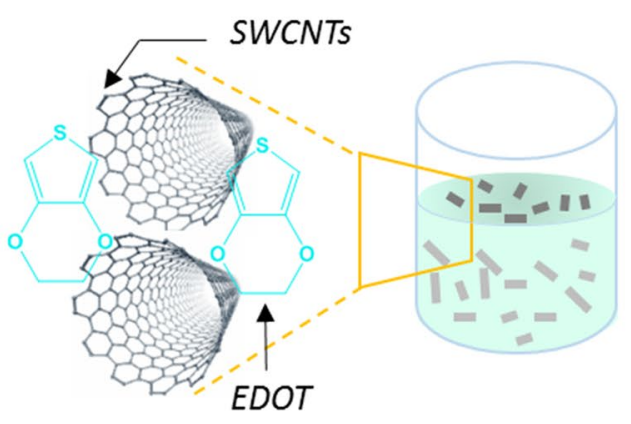

(a) Sonicated mixture of monomer and carbon nanoparticles

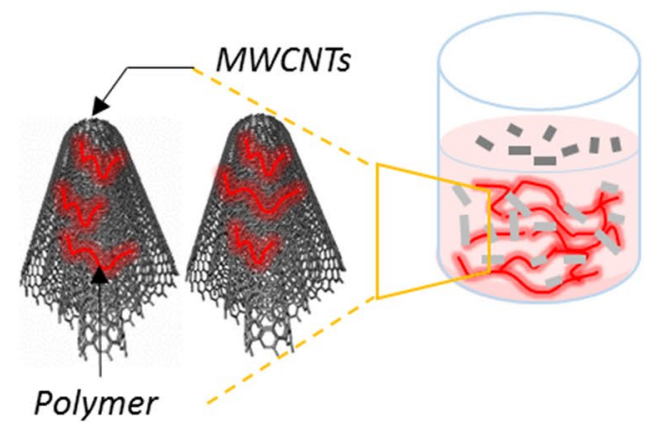

(b) Polymer dissolved, mixed and sonicated + carbon nanoparticles
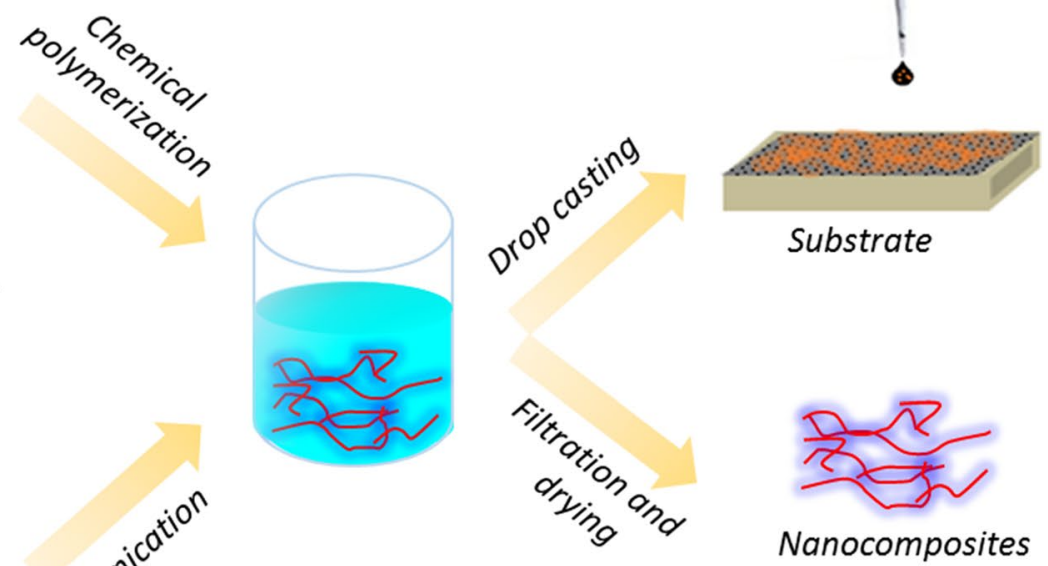

Substrate

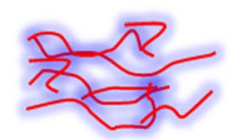

Nanocomposites

Powder

Fig. 2 Schematic illustration of chemical preparation method of CNMs/conducting polymer nanocomposites: a in-situ chemical polymerization of monomer and carbon nanoparticles, $\mathbf{b}$ sonication of commercial polymer solution and carbon nanoparticles 


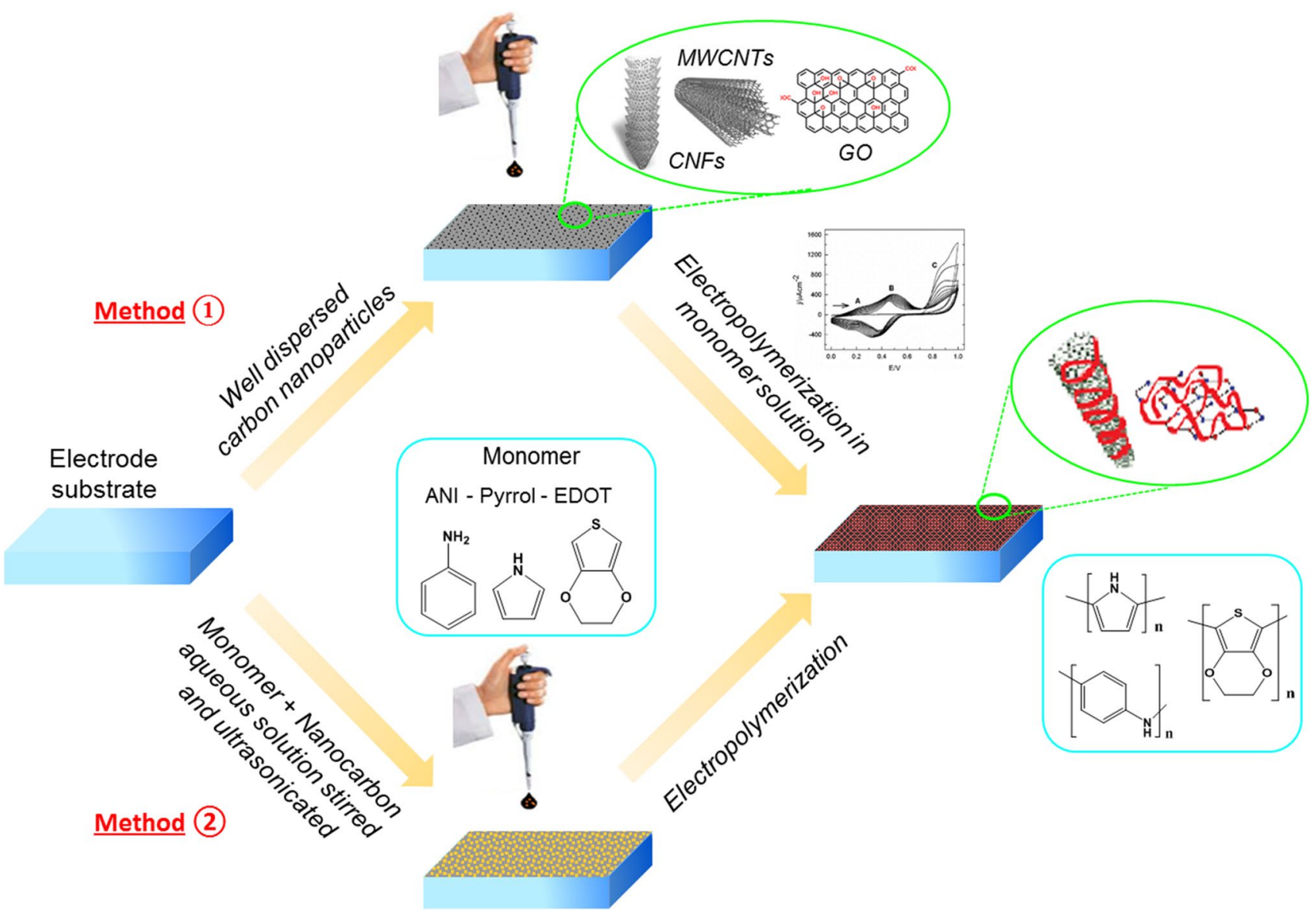

Fig. 3 Schematic illustration of electrochemical process of elaboration of CNMs/conducting polymer nanocomposites

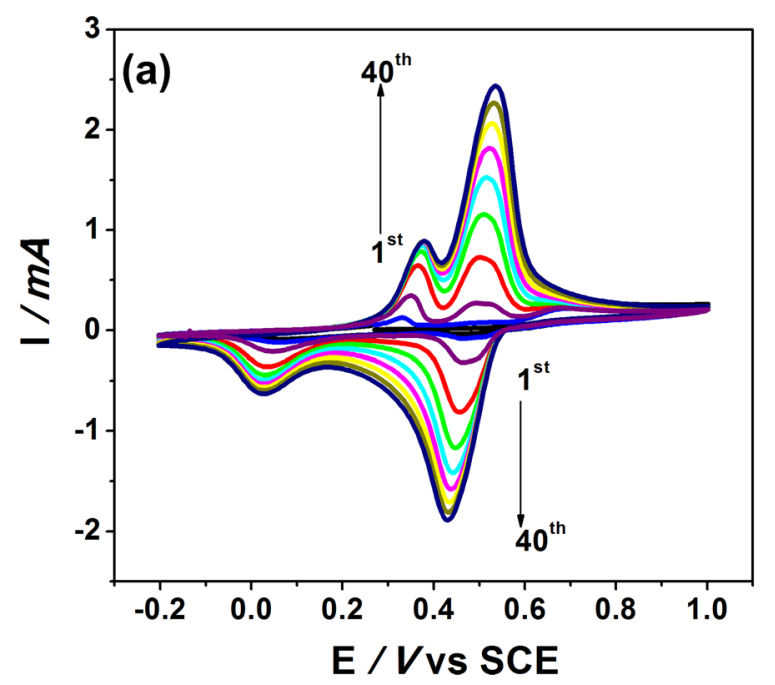

Fig. 4 a Cyclic voltammograms of electropolymerization of 1,5-DAN at the surface of $\mathrm{CPE} / \mathrm{CNF}$ during 40 consecutive potential cycles between -0.2 and $1.0 \mathrm{~V}$ in a $1.0 \mathrm{M} \mathrm{HCl}$ solution containing $5 \mathrm{mM}$

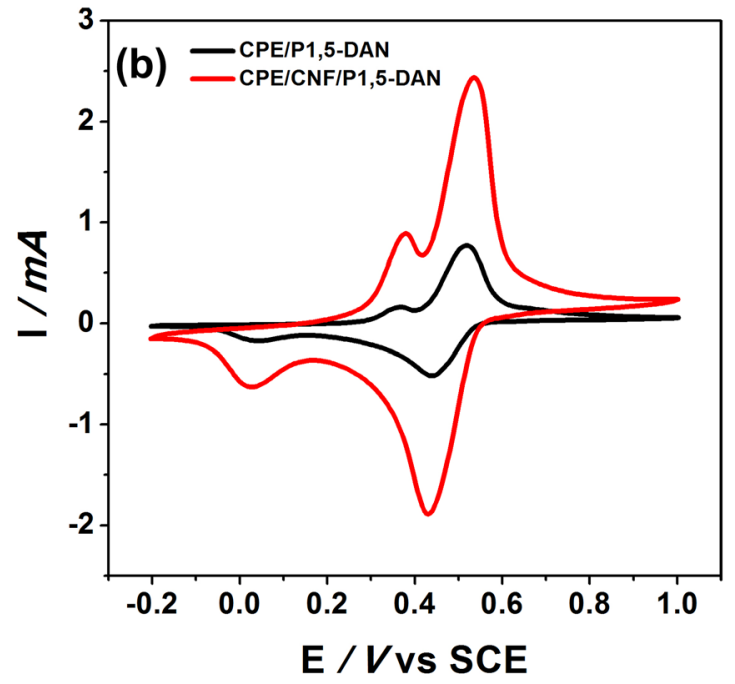

1,5-DAN, $50 \mathrm{mV} \mathrm{s}^{-1}$, b compared voltammograms between CPE/ poly (1,5-DAN) and CPE/CNF/poly(1,5-DAN) at the 40th cycle [65] 
The properties of these nanocomposites are also related to the percentage of CNMs. The percentage of CNM plays an important role on the mechanical and electrical properties of nanocomposites and was studied by different authors. The influence of the percentage of CNT in CNT/PANI composite was investigated by Liu et al., increasing the mass ratio of CNT to aniline, the diameter of core-shell polymer decreased, and therefore, the composite conductivity decreased also. Less than $10 \%$ by weight, the composite CNT/PANI showed a gradually increasing conductivity [69]. Gui et al. developed three PANI/graphene oxide (GO) nanocomposite electrode materials from aniline (ANI) and GO by chemical polymerization with the mass ratio (ANI/ GO) 1000:1, 100:1, and 10:1. The PANI/GO composite synthesized with the mass ratio (ANI/GO) 1000:1 possessed excellent capacitive behavior with a high specific capacitance due to the unique morphology of Mace-like PANI/GO composite [70]. It seems that the low percentage of carbon nanomaterials gives better results in them of conductivity and mechanical properties.

\section{Nanocomposites based on carbon nanotubes}

Since its discovery by Iijima in 1991, carbon nanotubes have revolutionized the field of polymer nanocomposites [71]. It was categorized as single-walled and multi-walled nanotubes. SWNTs are seamless cylinder graphite sheets. They have a diameter of $2 \mathrm{~nm}$ and a length of several micrometres, while MWNTs consist of multiple layers of graphene rolled in on themselves and separated from one another by $0.34 \mathrm{~nm}$. Their diameter varied between 2 and $20 \mathrm{~nm}$. A growing number of researchers worldwide have shown an interest in the combination of CNT with PANI. Recently, review articles have been published on the progress in the different synthesis methods of CNT/PANI nanocomposites. The identifications methods, the properties of the final product, and the progress towards technological applications have been investigated $[72,73]$. CNT/PANI composites can be synthesized by electrochemical or chemical processing. CNT functionality is the key to improve dispersion of the nanotubes in the liquid (aniline, solvent) and consequently in the CNT/PANI composite. It also helps to direct formation of PANI chains at the surface of CNT instead of bulk PANI. Due to their easy synthesis, processability and possibility to combine the properties of CNT and the properties of PANI with synergic effects, CNT/PANI composites present great interest for various applications as chemical sensors, capacitors, fuel cells, and electronic devices. Recently, MWCNTconducting polymer nanocomposites for gas-sensing applications were investigated. Mangu et al. demonstrated that the use of conducting polymers like polyaniline (PANI) and poly(3,4-ethylenedioxythiophene)-polystyrene sulfonic acid (PEDOT:PSS) enhances the gas-sensing capabilities. The
MWCNT-PANI composite sensor synthesized was observed to show superior sensitivities and excellent reversibility to 100 ppm of $\mathrm{NO}_{2}$ gas [62]. Later, Sharma et al. studied the thermal properties of the MWCNT-conducting polymer composite. They utilized MWCNT with PEDOT:PSS and PANI to develop high-temperature tolerant ammonia gas sensor. MWCNT-PEDOT:PSS composite was found to show better thermal stability than MWCNT-PANI composite. The MWCNT-PEDOT:PSS composite sensor was found to exhibit excellent response for trace level sensing (1-50 ppm) of ammonia gas than MWCNT-PANI composite [74]. Pure carbon nanotubes (CNTs) were also used to prepare PEDOT conducting polymer nanocomposite. Electrochemical polymerization of PEDOT/CNT nanocomposite was performed in EDOT aqueous solution containing only CNTs as the dopant. The solution was stirred and ultrasonicated for $10 \mathrm{~min}$ before polymerization at $1.2 \mathrm{~V}$ for $30 \mathrm{~s}$. Due to the excellent stability of the PEDOT/CNT nanocomposite and its catalytic property towards dopamine (DA), a highly stable and sensitive DA sensor was developed that performs favorably in the presence of a high concentration of the common interferant ascorbic acid [66].

Polypyrrole is also an interesting conducting polymer who has the structural uniformity and high conductivity by strong $\pi-\pi$ stacking between PPy conjugate backbone and graphitic sidewall of CNTs. To avoid all complicated multiple-step procedures to synthesize PPy/CNT-based nanocomposites, poly(sodium 4-styrenesulfonate) (PSS) polyelectrolyte has been added as supporting electrolytes as well as dopants to improve the solubility and dispersion of CNT. A one-step electrochemically polymerized method was used to fabricate the PPy/PSS-CNT composite electrodes. Thus, the aqueous solution for electrochemical polymerization consisted of pyrrole monomer, PSS, and long or short CNT. Comparing to the short CNT-incorporated PPy/PSS electrodes, long CNT-incorporated PPy/PSS electrodes show the relatively more superior capacitive behavior and cycle stability [75]. In other work, sodium dodecylbenzene sulfonate (SDBS) was used to disperse MWCNTs with ratio of 1:10 nanotubes to SDBS. MWCNTs, with different weight ratio $(0.3,0.5,0.7,0.9$, and $1.1 \%)$ to the pyrrole monomer, were dispersed and sonicated in an SDBS solution. Then, PPy-MWCNTs' layer was synthesized by electrochemical polymerization of distillated pyrrole on MWCNT. PPy/ MWCNT nanocomposite was used to improve the sensitivity and selectivity of sensors via interfacial interactions between MWCNTs and the conducting polymer. The nanocomposite layers were used to modify the gold layer to detect trace amounts of mercury $(\mathrm{Hg})$, lead $(\mathrm{Pb})$, and iron $(\mathrm{Fe})$ ions using the surface plasmon resonance technique [76]. Nanocomposite of PPy and carboxylated MWCNT was synthesized by chemical polymerization for different MWCNT weight ratios. Six PPy-MWCNT nanocomposite samples 
were prepared for different amounts of f-MWCNTs, and the weight ratio of functionalized MWCNT in PPy matrix varied from 0.25 to $8 \%$. The PPy-MWCNT nanocomposite pellet sensors showed good sensitivity to $\mathrm{NH}_{3}$ gas at room temperature. The most sensitive PPy-MWCNT nanocomposite sensor to $\mathrm{NH}_{3}$ gas was obtained with $4 \mathrm{wt} \%$ MWCNT ratio [77]. Polyphenazines and poly(triphenylmethanes) as conducting polymers were also combined with CNT to develop electrochemical sensors and biosensors. Barsan et al. published recently a review on preparation and characterization of conducting polymer/CNT composites based on these phenazine polymers. The specific combination of phenazine/ triphenylmethane polymers with CNT leads to an improved performance of the resulting sensing devices because of their complementary electrical, electrochemical and mechanical properties, and also due to synergistic effects. The main analytical applications as sensor were reported [78].

\section{Nanocomposites based on graphene}

Graphene oxide (GO) can be prepared in large scales from natural graphite. It was synthesized by a modified Hummers method as described in the previous studies [79]. It is a single sheet of graphite oxide-bearing oxygen functional groups on their basal planes. In recent years, GO has attracted great interest because of its superior mechanical, structural, and thermal properties and also its low cost compared to other conventional carbon nanomaterials like CNT. GO can be easily dispersed in aqueous solution and act as an excellent dopant for the chemical and electrochemical polymerization of conducting polymers due to the abundance of carboxyl groups that are negatively charged in aqueous solution. Kim et al. demonstrated that GO can play a role as a chemical oxidant for various CPs (polythiophene, polyaniline, and polypyrrole). In addition, diverse graphene/CP composites (graphene/polythiophene, graphene/polyaniline, and graphene/polypyrrole) can simply and rapidly be synthesized using the GO as both graphene precursor and chemical oxidant [80]. Poly[3,4ethylenedioxythiophene] was largely studied to synthesize (GO/PEDOT) nanocomposites. Luo et al. have successfully synthesized GO/PEDOT nanocomposites by cyclic voltammetry using graphene oxide as dopant. The resulting nanocomposite is highly biocompatible with neuronal cells [68]. Due to their many negatively charged carboxyl groups, GO is an excellent dopant for the electropolymerization of conducting polymers. The formed film contains functional groups promoting any modification of the surface of the nanocomposite film. These groups reach carboxyl groups of GO partially exposed to the surface of the film PEDOT/GO. Normally, GO is an electrically insulating material, but its conductivity is recovered by restoring its network through its reduction to form what is called graphene or reduced graphene oxide. This reduction can be done thermally, electrochemically, or chemically using strong reducing agents such as hydrazine or sodium borohydride. GO is also an attractive platform for the production of functionalized graphene platelets with improved mechanical, thermal, and/or electronic properties [81-84]. Ambrosi and Pumera confirmed later that the electrochemical reduction is more interesting, because this process allows to control accurately the obtained chemical structures of graphene with reproducible density of the oxygen functionalities PEDOT/GO nanocomposite of reduced GO-doped conducting polymer PEDOT was prepared to improve electrochemical catalytic property of the resulting nanocomposite [85]. The same nanocomposite was electrodeposited on GCE and followed by electrochemical reduction. The obtained modified electrode was used as a sensitive sensor for DA detection without ascorbic and uric acids interference [86]. Seekaew et al. performed a gas sensor based on graphene-PEDOT:PSS composite film. Incorporating graphene in the polymer increased the specific adsorption surface area which has improved the $\mathrm{NH}_{3}$ response [87]. The preparation and the thermoelectric proprieties of PEDOT composites containing PEDOT, reduced graphene oxide (RGO), and singlewalled CNT (SWCNT) were also reported by Li et al. [88]. Nanocomposites based on PPy and GO exhibited enhancement in electrical conductivity. Bora et al. synthesized polypyrrole (PPy)/graphene oxide (GO) nanocomposites via liquid/liquid interfacial polymerization. The developed $\mathrm{PPy} / \mathrm{GO}$ nanocomposite, comparing to pure polypyrrole, has shown improvement in electrical conductivity [89]. In another work, GO/PPy nanocomposites were performed by a one-step co-electrodeposition method. During the pyrrole electropolymerization, a negative charge of GO was incorporated into the polymer to balance the positive charge on the polymer. Moreover, the $\pi-\pi$ interactions between GO and PPy play a considerably role in the formation of GO/PPy nanocomposites [67]. Overoxidized polypyrrole (PPyox) was used to synthesize PPyox/graphene nanocomposite due to their cation exchange and molecular sieve properties. The nanocomposite-modified GCE has been prepared and applied as dopamine sensors without the interference of ascorbic acid [64]. GO/PPy was also used to prepare molecularly imprinted polymer (MIP) for quercetin detection [63]. In the same way, the reduced form of graphene was combined with PPy for application as supercapacitors or sensors [90]. As example of sensor, Rong et al. have prepared GO/PPy by reducing GO to RGO and polymerization of PPy using potentiostatic mode. The resulted nanocomposites were applied for ammonia and $\mathrm{Pb}^{2+}$ detection [91]. In a comparative study, properties of PANI/G and PANI/MCWNT nanocomposites were investigated. It was proved that the charge transfer between the 
PANI and carbon materials (MWCNTs and G) improved the electrical conductivity of PANI. The obtained composites have different morphologies and conductivities. It was elucidated that PANI/G composite has a plate form, while PANI/MCWNT composite is tubular [92]. An electrochemical biosensor based on PANI/RGO nanocomposite has been reported. The nanocomposite was synthesized by chemical oxidative polymerization method and was then used as the sensitive layer of a DNA adsorbent for detecting $\mathrm{Hg}^{2+}$. The detection limit was $0.035 \mathrm{nM}$ [93]. Nguyen et al. synthesized PANI grafted RGO composites via a two-step method. First, RGO was modified with 1,3-diaminopropane providing reactive $\mathrm{NH}_{2}$ groups on surface witch can polymerize with aniline. The formed $\mathrm{GO}-\mathrm{NH}_{2}$ was then grafted with polymer chains by in situ chemical polymerisation. The RGO-g-PANI composites were used for the chemical detection of hydrogen peroxide in aqueous solutions [94]. The G/PANI-modified electrode allowed selective determination of the target metals in the presence of bismuth Bi(III). Graphene-polyaniline (G/PANI) nanocomposite was used to develop an electrochemical sensor for simultaneous detection of $\mathrm{Zn}(\mathrm{II}), \mathrm{Cd}(\mathrm{II})$, and $\mathrm{Pb}(\mathrm{II})$. To prevent nanoparticle aggregation during nanocomposites synthesis, they added polyvinylpyrrolidone (PVP) by a method called reverse dropping which creates a solution of well-dispersed particles [95]. Under optimal conditions, the detection limits were $1.0 \mu \mathrm{g} \mathrm{L}{ }^{-1}$ for $\mathrm{Zn}$ (II) and $0.1 \mu \mathrm{g}$ $\mathrm{L}^{-1}$ for both $\mathrm{Cd}(\mathrm{II})$ and $\mathrm{Pb}(\mathrm{II})$. Recently, electrospun graphene/polyaniline/polystyrene (G/PANI/PS) nanoporous fiber-modified screen-printed carbon electrode was investigated and optimized also to simultaneous determination of $\mathrm{Pb}^{2+}$ and $\mathrm{Cd}^{2+}$ in the presence of bismuth. The limits of detection were found to be $3.30 \mu \mathrm{g} \mathrm{L}^{-1}$ for $\mathrm{Pb}^{2+}$ and $4.43 \mu \mathrm{g} \mathrm{L}^{-1}$ for $\mathrm{Cd}^{2+}$ [96]. Poly(diaminonaphthalene) combined with RGO was synthesized in one step using cyclic voltammetry. The chelating capacity of poly $(1,5$ diaminonaphthalene) and the properties of RGO were used to elaborate a lead sensor [97].

\section{Nanocomposites based on carbon black}

Only one paper is devoted to carbon black. Mallya et al. used a nanocomposite of a novel thiophene-based conducting polymer and carbon black as a volatile organic compound sensor. The obtained sensors were tested for the determination of toluene, acetone, carbon tetrachloride, and cyclohexane and showed maximum response to toluene [98]. Since the low cost of carbon black more research must be conducted in this area.

In conclusion, the carbon nanomaterials and conducting polymer nanocomposites are very promising materials because of multifunctional and unique properties. Therefore, such nanocomposites have been reported in the literature as promising prototype materials for chemical sensors applications, as it is summarized in Table 1.

\section{Nanocomposites synthesized by combination of metal nanoparticles and conducting polymers}

Nanocomposites based on conducting polymers (CPs) and metal nanoparticles (MNPs) are a new class of nanomaterials that have received a considerable attention during the last decade [104]. These nanocomposites are formed by combining the unique properties of MNPs and CPs, in the aim to enhance the chemical and/or physical properties. The combination of these materials can give rise to a new nanostructure with novel properties and promising potential applications in various fields of nanoscience and nanotechnology. Recently, many efforts have been made to synthesize new nanocomposites of conducting polymers and metal nanoparticles with new properties and applications $[105,106]$.

In this part, we will give an overview about the most method used to synthesis different metal nanoparticles such as $\mathrm{Au}, \mathrm{Pt}, \mathrm{Pd}, \mathrm{Ag}, \mathrm{Cu}$, and $\mathrm{Bi}$. We will also discuss the main parameters affecting their structural, physical, and chemical properties. On the other hand, a special attention will be paid to the recent advances in the synthesis of nanocomposites based on metal nanoparticles and conducting polymers such as polythiophene (PTh), polypyrrole (PPy), polyaniline (PANI), poly(3,4-ethylenedioxythiophene) (PEDOT), and their derivatives. We will also focus on their current catalytic and sensing applications.

\section{Different strategies for the synthesis of metal nanoparticles}

Metal nanoparticles could be prepared using two different approaches, which are bottom-up and top-down. In the first approach, the metal nanoparticles are fabricated by starting from metals atoms dissolved in aqueous or organics solution and then deposed under appropriate experimental conditions. In the second approach, the metal nanoparticles are prepared by subdivision of bulk metals usually using physical methods [107, 108]. Considering the above approaches, the methods of synthesis of metal nanoparticles could be classified to six mean methods, as shown in Fig. 5.

The chemical reduction is considered the common method reported in the literature for the synthesis of metal nanoparticles, which are formed by reducing metal salts in the presence of an appropriate reducing agent and a stabilizer usually a special ligand, polymer, or surfactant. The electrochemical methods are widely used in the synthesis of metal nanoparticles. The metal species is dissolved in 
Table 1 Typical applications of CNMs/conducting polymer nanocomposites as sensor

\begin{tabular}{|c|c|c|c|c|c|c|}
\hline Nanocomposite & Polymer & CNM & Application & LOD & Characterization & Refs. \\
\hline PEDOT/GO & PEDOT & GO & Dopamine detection & $39 \mathrm{nM}$ & EIS-SEM & [86] \\
\hline $\begin{array}{l}\text { MWCNT-PEDOT:PSS } \\
\text { MWCNT-PANI }\end{array}$ & $\begin{array}{l}\text { PEDOT:PSS } \\
\text { PANI }\end{array}$ & MWCNT & Ammonia gas sensor & & FTIR-SEM-TEM & [74] \\
\hline SEBS/MWCNT & SEBS & MWCNT & Temperature sensors & & TGA, SEM & [99] \\
\hline PPyox/graphene & PРyox & graphene & Detection of Dopamine & $0.1 \mu \mathrm{M}$ & SEM & [64] \\
\hline MIP/GO & PPy & Graphene oxide & Quercetin determination & $48 \mathrm{nmol} \mathrm{L}^{-1}$ & & {$[63]$} \\
\hline MWNTsg-PtBMA- $b$-PS & PS- $b$-PtBMA & MWNTs-COOH & $\mathrm{CHCl}_{3}$ vapor sensor & & $\begin{array}{l}\text { FTIR, 1H NMR, TGA } \\
\text { XRD, TEM, SEM }\end{array}$ & [100] \\
\hline PEDOT/CNT & PEDOT & CNT & Dopamine detection & $20 \mathrm{nM}$ & SEM, CV & {$[66]$} \\
\hline G/PANI & PANI & graphene & $\begin{array}{l}\mathrm{Zn}(\mathrm{II}) \\
\mathrm{Cd}(\mathrm{II}) \\
\mathrm{Pb}(\mathrm{II})\end{array}$ & $\begin{array}{l}1 \mu \mathrm{g} \mathrm{L}^{-1} \\
0.1 \mu \mathrm{g} \mathrm{L}^{-1} \\
0.1 \mu \mathrm{g} \mathrm{L}^{-1}\end{array}$ & SEM, FTIR, CV & [95] \\
\hline G/PANI/PS & PANI/PS & graphene & $\begin{array}{l}\text { Simultaneous determina- } \\
\text { tion of } \mathrm{Pb}^{2+} \text { and } \mathrm{Cd}^{2+}\end{array}$ & $\begin{array}{l}3.30 \mu \mathrm{g} \mathrm{L}^{-1}\left(\mathrm{~Pb}^{2+}\right) \\
\quad 4.43 \mu \mathrm{g} \mathrm{L}^{-1} \\
\left(\mathrm{Cd}^{2+}\right)\end{array}$ & SEM, TEM, BET & [96] \\
\hline 3D-rGO@PANI & PANI & 3D-RGO & Detection of $\mathrm{Hg}^{2+}$ & $0.035 \mathrm{nM}$ & XPS, SEM & [93] \\
\hline $\begin{array}{l}\text { Poly(DTCPA-co- } \\
\text { BHTBT)-CB }\end{array}$ & $\begin{array}{l}\text { poly } \\
\text { (DTCPA- } \\
\text { co- } \\
\text { BHTBT) }\end{array}$ & carbon black & $\begin{array}{l}\text { Volatile organic com- } \\
\text { pounds (VOCs) sensor }\end{array}$ & $15 \pm 10 \mathrm{ppm}$ & $\begin{array}{l}\text { UV-vis, optical pro- } \\
\text { filometer contact angle } \\
\text { measurements AFM, } \\
\text { FEG SEM }\end{array}$ & [98] \\
\hline GO-PANI & PANI & GO & $\begin{array}{l}\text { Carbaryl, carbofuran, } \\
\text { methomyl }\end{array}$ & $\begin{array}{l}0.136 \mathrm{mg} \mathrm{L}^{-1} \\
0.145 \mathrm{mg} \mathrm{L}^{-1} \\
0.203 \mathrm{mg} \mathrm{L}^{-1}\end{array}$ & $\begin{array}{l}\text { CV, UV-Vis and FTIR } \\
\text { spectrometry }\end{array}$ & [101] \\
\hline PEDOT/GO & PEDOT & $\mathrm{GO}$ & Mercury (II) & $2.78 \mathrm{nM}$ & SEM, TEM & [102] \\
\hline G/p-AHNSA & $p$-AHNSA & Graphene & $\begin{array}{l}\text { Dopamine (DA) and } \\
\text { 5-hydroxytryptamine } \\
(5-\mathrm{HT})\end{array}$ & 2 and $3 \mathrm{nM}$ & CV, SWV, EIS, SEM & [103] \\
\hline
\end{tabular}

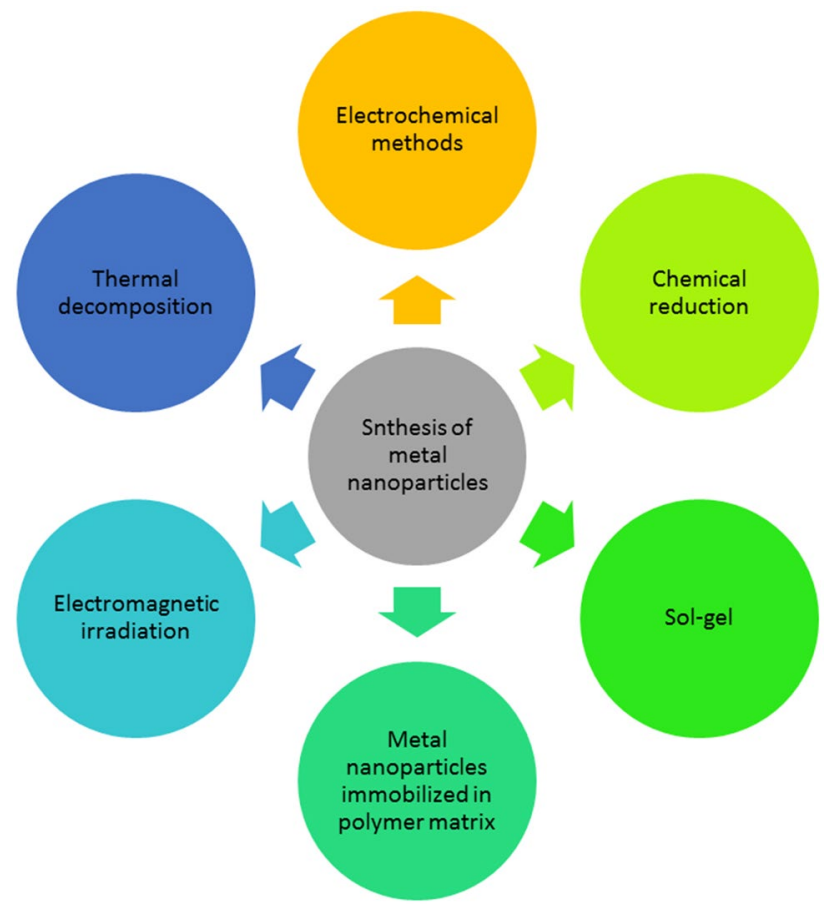

Fig. 5 Different methods used for the synthesis of metal nanoparticles aqueous or organics solution, then followed by the reduction of metal ions on an appropriate support using cyclic voltammetric or a constant reduction potential.

- Metal nanoparticles immobilized in polymer matrix

In general, there are three ways to obtaining metal nanoparticles within polymer matrix, including dispersion, deposition, and immersion. The dispersion method starts with mixing metal precursor with protective polymer and the metal ions are subsequently reduced in the solution. In deposition process, metal precursor which was mixed with protective polymer is deposited onto a substrate.

- Sol-gel

Sol-gel methods are also considered as a very promising method for the synthesis of metals nanoparticles [109]. During their synthesis, the experimental conditions including $\mathrm{pH}$, nature of solvent, and temperature strongly affects on properties of the synthesized metal nanoparticles.

- Electromagnetic irradiation

The metal nanoparticles could also be prepared using electromagnetic irradiation methods including UV, microwave, ultrasonic, and laser irradiation [110, 111].

- Thermal decomposition 
Another way for the synthesis of metal nanoparticles is heating volatile metal compounds in organic media or gas phase. The compounds degrade and liberate metal or the corresponding metal oxide in dispersed phase.

\section{Nanocomposites based on conducting polymers and metal nanoparticles}

There are four basic strategies for the preparation of the nanocomposites of conducting polymers and metal nanoparticles as mentioned in the review of Kondeatiev et al., the commonly used procedures for preparation of nanocomposite are:

Electrochemical method: the deposition of metal nanoparticles into the pre-synthesized polymer film, or during the electropolymerization process.

Chemical method: the nanocomposite can also be performed from colloid dispersions of polymers and metal nanoparticles, or in one-step synthesis from mixed solution containing monomer and metal ions. Conducting polymer-metal composites are obtained by oxidizing the conjugated monomer by transition metal cations, which induces the simultaneous formation of both the polymer matrix and the metal nanoparticles. Figure 6 summaries the most procedure used for preparation of these nanocomposite.

In addition, the electrochemical or chemical methods for synthesizing conducting polymer-metal nanocomposite are considered as well as the main factors affecting the structure and electrochemical properties of these composites [34]. The size of the synthesized nanocomposite was approximately ranging from 1 to $100 \mathrm{~nm}$. The shape and size of the nanocomposite obviously depend on methods of deposition of metal nanoparticles and the shape of conducting polymers $[40,112]$. The modification of some conducting polymers such as polythiophene (PTh), polypyrrole (PPy), and polyaniline (PANI) by serval metal nanoparticles was reported [113]. The obtained nanocomposites were used in
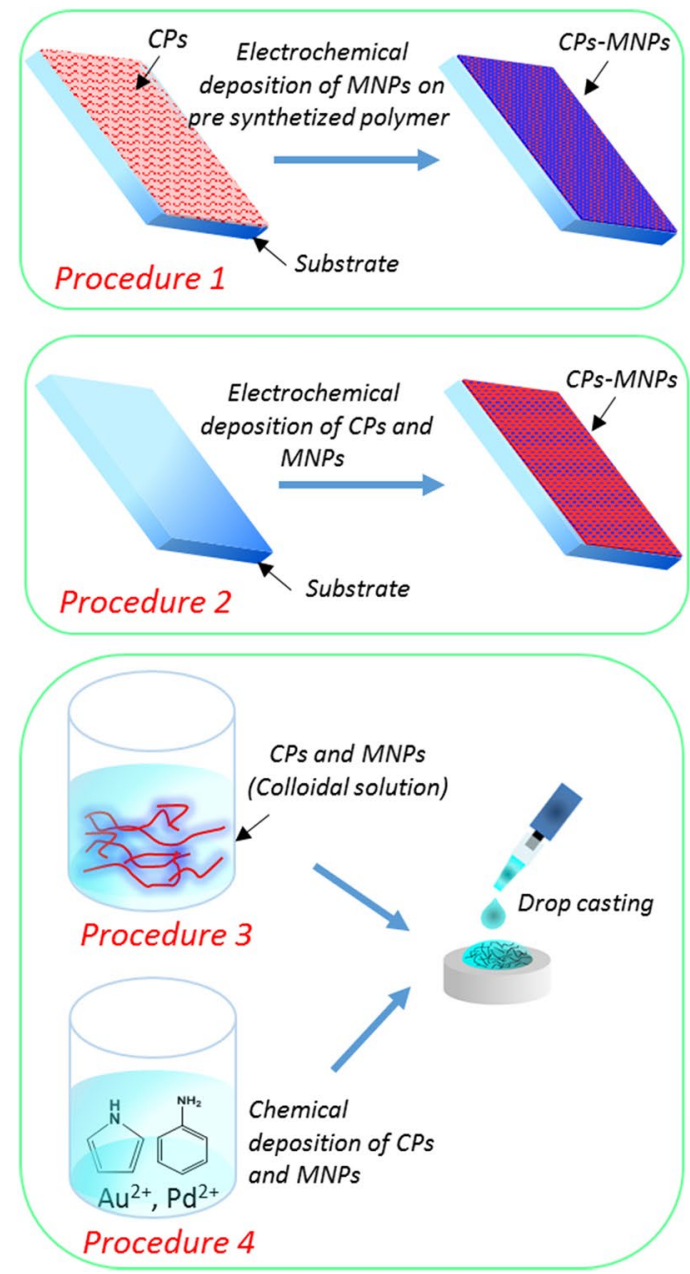

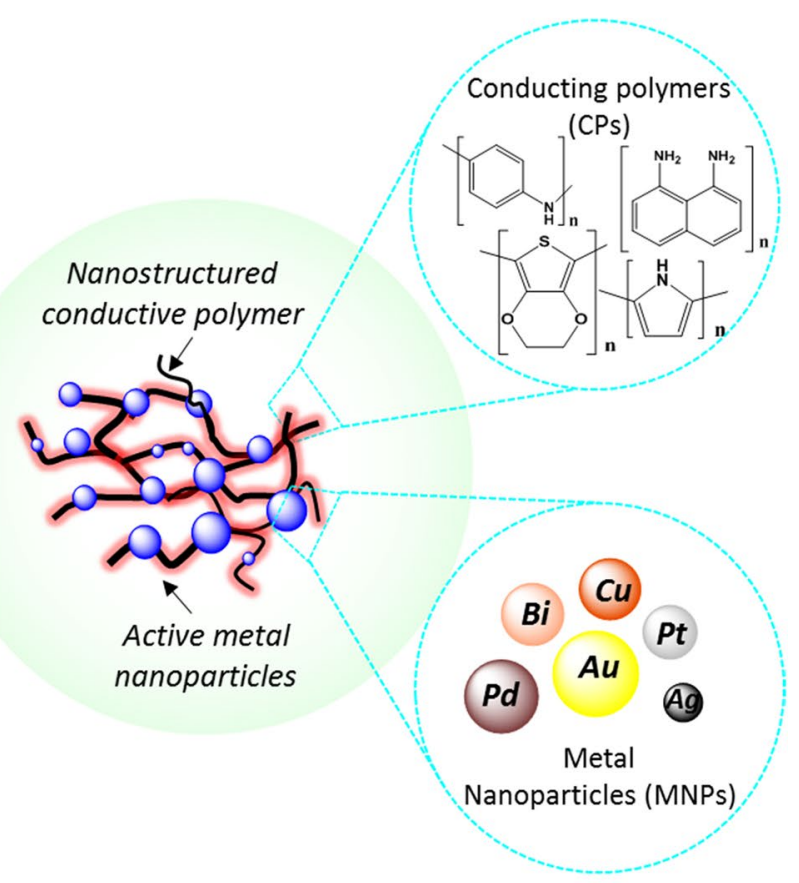

Fig. 6 Schematic illustration of the most procedure for the preparation of nanocomposites based on conducting polymer and metal nanoparticle CPs/MNPs 
electrochemical sensors [114], energy technology, batteries, and fuel cells $[115,116]$.

\section{Gold nanoparticles-polymer}

Gold nanoparticles are widely used due to their very interesting properties and their catalytic power. The conducting polymers with gold nanoparticles as a nanostructured materials exhibit unique electrical, optical, and catalytic properties. These nanocomposites have been utilized for heavy metal, nitrite, ammonia gas, $\mathrm{H}_{2} \mathrm{O}_{2}$, dopamine, glucose, ascorbic acid, and uric acid detection. Different methods for preparation of nanocomposites AuNPs/CPs are used such as chemical, electrochemical, thermal evaporation, hydrothermal, and spin-coating method. At present, it has been found that the best way to synthesis polymer-metal nanocomposite is the deposition of metal nanoparticles into the polymer film. Metal nanocomposite is formed on the surface or in the bulk by drop casting or incorporation of pre-synthesized NPs during the electrochemical deposition of conducting polymer, as shown in Fig. $6 . \mathrm{HAuCl}_{4}$ was used as a precursor for the preparation of AuNPs/polymer with a concentration from 3 to $10 \mathrm{mM}$. The size of the AuNPs is related to $\mathrm{Au}$ precursor concentration, polymer/AuNPs molar ratio, synthesis method, and synthesis time [117-122]. Huang et al. have developed a facile and well-controlled techniques to prepare water dispersible uniform AuNPs on PANI. Uniform gold nanoparticles with a size around of $2 \mathrm{~nm}$ were selectively reduced on polyaniline nanofibers, from aqueous solution of $\mathrm{HAuCl}_{4}$. The strong interaction between protonated amine and $\mathrm{AuCl}_{4}{ }^{-}$leads to an excellent electrocatalytical effect. The modified electrode exhibited a fast response time and high sensitivity for $\mathrm{H}_{2} \mathrm{O}_{2}$ sensing with a detection limit of $0.1 \mu \mathrm{M}$ [117]. The same authors developed an electrochemical sensor for the oxidation of dopamine on molybdenum disulfide nanosheets-polyaniline (MoS-polyaniline) composites and gold nanoparticles (AuNPs)-modified glassy carbon electrode with a size of $13 \mathrm{~nm}$. The graphene-like MoS-polyaniline composites were synthesized by hydrothermal method and a simple in situ polymerization procedure. The electrochemical sensor was applied to the dopamine detection in human urine sample [118]. Two approaches to incorporate the AuNPs with and without pre-functionalization into covalently assembled polythiophene films have been reported (NPs size $14.5 \pm 4 \mathrm{~nm}$ ). The adopted approaches involve alternate deposition of monomeric and polymeric species for creating multilayers. This method has been used to develop facile method for nanoparticles incorporation and to facilitate direct interaction between conducting polymers and nanoparticles. Both the approaches have merits and demerits on their own depending on the film requirements. However, the preparation of this nanocomposite takes a very long time (more than
6 days) [123]. In other work, the co-polymerization of polyvinylpyrrolidone and polyaniline was performed by cyclic voltammetry. The nanocomposite of gold nanoparticles with co-polymer was synthesized by electrodeposition methods on a glassy carbon electrode (GCE) in a homogeneous threecomponent solution consisting of aniline, PVP, and AuNPs. The modified electrode was used as glucose biosensor [124]. Recently, a nanocomposite of the self-assembly gold of nanoparticles with polystyrene- $b$-poly (4vinylpyridine) copolymer has been synthesized with a size of $27 \mathrm{~nm}$ for (bio) sensing applications [121]. Spherical gold nanoparticles, with a size of $3.5 \mathrm{~nm}$, were used for preparation of glucose biosensors in the presence of conducting polymer and were successfully applied to beverages for the detection of glucose content in a linear range between 0.025 and $1.25 \mathrm{mM}$. The detection limit was $0.025 \mathrm{mM}$ [125]. An approach to elaborate a novel nanocomposite in which gold nanoparticles in small size $(4.2 \mathrm{~nm})$ are dispersed on polypyrrole matrix has been developed by Zhang et al. [119]. The nanocomposite has showed great potential for detecting ammonia gas at room temperature. In addition, the bioimprinted ds-DNA and Au nanoparticles in the o-phenylenediamine were used to modified pencil graphite electrode as sensor for the determination of dopamine. This nanocomposite was prepared by electrochemical entrapment of ds-DNA and Au nanoparticles in the o-phenylenediamine. The nanocomposite was applied for the determination of dopamine in biological samples over the range of $20-7000 \mathrm{nM}$ with a detection limit of $6 \mathrm{nM}$ [122]. El-said et al. have synthesized poly(4-aminothiophenol) nanostructures layered on gold nanodots patterned indium tin oxide (ITO) electrode. The modified gold nanodots ITO electrode were fabricated by thermal evaporation of pure gold metal onto ITO surface through polystyrene monolayer. Then, a monolayer of 4-aminothiophenol was self-assembly immobilized onto the gold nanodots array/ ITO electrode by electrochemical polymerization process. The size of AuNPs was $80 \mathrm{~nm}$. The obtained electrode was used for detection of adenine and guanine in human serum sample [126]. The nanocomposite-based gold nanoparticles are usually decorated on molecularly imprinted polymer membranes (MIPM). In the work of Zhang et al., MIPM was used as biomimetic molecular recognition element involved in o-aminothiophenol functionalized Au nanoparticles (ATP-AuNPs) with a size of AuNPs $4.2 \mathrm{~nm}$. The modified gold electrode was used for detection of herbicide simazine (SMZ) in several real samples. The linear dependency of peak current on SMZ concentrations was observed from 0.03 to $140 \mu \mathrm{M}$ and detection limit was estimated to be $0.013 \mu \mathrm{M}$ [120]. In a recent paper, an approach for synthesis of PEDOT/AuNPs composite was developed by Lin et al., consisting of electropolymerization of PEDOT from solution containing gold nanoparticles and EDOT monomer mixed in water solution. It was demonstrated that sensor is 
highly stable, sensitive, and selective and it was used for the detection of nitrite in tap water [127]. Sadanandhan and Devaki have modified the glassy carbon electrode with PANI through electrochemical polymerization by cyclic voltammetry. Then, the gold nanoparticle AuNPs were deposited by chronoamperometry on the polymer. The performance of the sensor was then tested in blood samples for simultaneous sensing of dopamine, ascorbic acid, serotonin, and uric acid [128].

\section{Platinum nanoparticles-polymer}

The interesting properties of platinum at nanoscale dimension have gained research attention due to their potential application. The platinum nanoparticles are considered very effective as a matrix in detection of various kinds of biomolecules and macromolecules such as DNA, enzymes, other proteins, and antibodies. The same strategies used in the deposition of gold nanoparticles were used for the deposition of platinum leading to a nanoparticles with diameter ranging from $1 \mathrm{~nm}$ to some hundreds $\mathrm{nm}$ using $\mathrm{PtCl}_{3}$ and $\mathrm{H}_{2} \mathrm{PtCl}_{6}$ as a precursor. The size and the distribution of platinum nanoparticles on the polyaniline and polypyrrole have been studied by varying the polymer matrix from nanofibers to nanotubes. The nanocomposites formed are very sensitive to the matrix morphologies. Small polymer nanostructure (nanofibers) provides a large number of heterogeneous nucleation sites for nucleating Pt nanoparticles, leading to better distribution and dispersion of the Pt nanoparticles (2 nM) [129]. Mishra et al. designed a new biosensor for the detection of human $\mathrm{C}$-reactive protein $(\alpha \mathrm{CRP})$, by combining two types of advanced materials with complementary properties, polypyrrole film (PPy) and platinum nanoparticles (PtNPs). The long chain of PPy in the polymer composite acts as a space between the biomolecules and the transducer, wherein the Pt nanoparticles help in preserving the native protein conformation and reducing the steric hindrance for better probe orientation and accessibility of the biomolecules to the analyte. The obtained nanocomposite has demonstrated a large surface area and a high performance towards Ag $\alpha$ CRP detection [130]. In the paper of Adeloju et al., the surface of the platinum electrode was first modified by thin film of platinum nanoparticles with a diameter of 30-40 nm priory the deposition polypyrrole film, providing large surface area for the deposition of ultrafine film polypyrrole. This strategy was employed to elaborate a biosensor for potentiometric detection of sulfite in wine and beer samples in the linear concentration range that extends from 0.75 to $65.50 \mu \mathrm{M}$ of sulfite, with a detection limit of $12.4 \mathrm{nM}$, and a response time of 3-5 s [131]. Boomi and co-works reported the first chemical synthesis of the polyaniline-modified Pt-Pd nanoparticles. The obtained nanocomposites exhibited improved antibacterial activity when compared to pristine polyaniline and individual metal colloids. The Pt-Pd nanoparticles have spherical morphology and the particles' size was found around of 1-7 nm. The antibacterial properties depend strongly on the size of metal nanoparticles [132]. In addition, Zhai et al. fabricated an electrochemical biosensor for glucose with Pt nanoparticle/polyaniline hydrogel hetero structures. This biosensor was applied for glucose enzyme sensor with a wide linear calibration ranging from 0.01 to $8 \mathrm{mM}$ and the detection limitation of $0.7 \mu \mathrm{M}$ [133].

\section{Silver nanoparticles-polymer}

Hybrid nanocomposites based on conducting polymers (CPs) and silver nanoparticles (AgNPs) have recently become a tool in the preparation of new materials. The obtained nanomaterials exhibit a good level of electrical conductivity as well as tunable physical, chemical, and responsive properties. Several conducting polymers were used to produce these nanocomposites among them, polypyrrole (PPy), and polyaniline (PANI) [134].

In a detailed review, the strategies of fabrication of nanocomposite by combination of silver nanoparticles (AgNPs) and conducting polymers and their application have been reported. Various strategies for the synthesis of AgNPs were detailed such as, polyol process, solvothermal method, ultraviolet irradiation, photo-reduction technique, electrodeposition process, DNA template method, porous material template method, and wet chemical method. The role of various additives (inorganic anions, metal cations, and organic molecular species) on the aspect ratio of silver nanowires (AgNWs) has been reported. Moreover, different methods for the preparation of AgNWs/conducting polymers composite film are reviewed like spin coating, dip coatings and electro-hydrodynamic (EHDA), simple solution mixing techniques, and electrospinning [135]. Nia et al. reported a new nanocomposite sensors based on polypyrrole (PPy) decorated with silver nanoparticles (AgNPs) and its application as a non-enzymatic sensor for hydrogen peroxide $\left(\mathrm{H}_{2} \mathrm{O}_{2}\right)$ detection. AgNPs-PPy was deposited on glassy carbon electrode by electrochemical method using cyclic voltammetry. The modified electrode revealed that PPy and AgNPs were uniformly formed and PPy was decorated with small particle size of AgNPs around of $25 \mathrm{~nm}$ [136]. In another application, Ghanbari has modified the glassy carbon electrode (GCE) with a pre-synthesized polypyrrole (PPy) nanofiber and then with AgNPs to form a nanocomposite of AgNPs/ PPy/GCE. The modified electrode was used to determination of hydrazine with a detection limit of $2 \mu \mathrm{M}$ [137]. It was reported in many studies that plants have potential to reduce metal ions both on their surface and in various organs and tissues. Alam et al. have used Ziziphus mauritiana fruit extract to synthesized sliver nanoparticle AgNPs. Then, 
the enzyme of alcohol dehydrogenase (YADH) has been immobilized on chemical synthesized polyaniline-coated AgNPs [138]. This approach has been actively studied in recent years as an alternative, efficient, inexpensive, and environmentally safe method for producing nanoparticles with specific properties.

Zang et al. have reported the preparation of a new nanocomposite based on AgNPs-PPy-modified attapulgite (ATP) as a clay support by in situ UV-induced dispersion polymerization. AgNPs with a size around of $40 \mathrm{~nm}$ were obtained and the potential applications of obtained composite nanoparticles as an antibacterial agent was explored [139]. Recently, Bhadra et al. used polyaniline (PANI) and polyvinyl alcohol (PVA) with silver nanoparticles to synthesis the nanocomposite blend (PNPAg). Nanocomposites with lower $\mathrm{Ag}$ concentrations have highly aligned PNPAg nanofibers of diameter $50-80 \mathrm{~nm}$ and agglomerations compared to the higher concentrations of Ag and have good optical and electrical properties. Indeed, the room temperature electrical conductivity of the nanocomposites increased with Ag nanoparticles [140].

\section{Palladium nanoparticles-polymer}

Palladium nanoparticles (PdNPs) have been used in a variety of fields, especially as catalysts in organic reactions due to their superior chemical stability and catalytic activity [141]. Few works have been reported in the literature for developing the nanocomposites by the combination of palladium nanoparticles (PdNPs) and conducting polymers (CPs). Prodromidis et al. reported a simple electroless approach for the synthesis of PdNPs incorporated in polyaniline (PANI) via formation of a preorganized palladium polymer complex material followed by slow reduction. The PdNPs were uniformly dispersed in the polymer with a diameter size around 5-10 nm and a large electrochemically active surface area. The obtained nanocomposite was applied for electrooxidation of methanol and ethanol. The results suggest that this nanocomposite could be considered as an efficient anode in fuel cells [142]. In an excellent research work, Li et al. reported a facile strategy to produce a novel nanoparticulate polyacetylene-supported Pd(II) catalyst [NP-Pd(II)] for use in the aqueous Suzuki-Miyaura cross-coupling reaction, by simply treating an aqueous solution of $\mathrm{PdCl}_{4}{ }^{2-}$ with acetylene under ambient conditions. The nanocomposites reveal homogeneous distribution of the $\mathrm{Pd}(\mathrm{II})$ along the polyacetylene and the aggregation of the NP-Pd(II) with diameters of 2-3 nm that make this nanocomposite an ideal catalyst combining the advantages of both homogeneous and heterogeneous catalysts [143]. Sapurina et al. recently reported that polypyrrole nanotubes, prepared by chemical reaction in the presence of methyl orange, could be used as a conducting substrate for the deposition of noble-metal nanoparticles. The synthesized polypyrrole nanotubes were decorated with palladium, platinum, rhodium, or ruthenium nanoparticles by carbonization method. The catalytic activity of obtained composites was proved in the reduction of 4-nitrophenol to 4-aminophenol [144]. In addition, Hosseini et al. synthesized palladium nanoparticles/poly $(3,4-$ ethylenedioxythiophene) nanofibers as a sensors for glucose and hydrogen peroxide detection by chronoamperometric method. This sensor shows a low detection limit of $1.6 \mu \mathrm{M}$ for glucose and $0.05 \mu \mathrm{M}$ for $\mathrm{H}_{2} \mathrm{O}_{2}$ in the range of 0.04-9 mM and $0.2-25 \mu \mathrm{M}$, respectively [145].

\section{Other metal_polymer nanocomposites}

Besides gold, platinum, palladium, etc, others metallic nanoparticles have been studied during the last decade such as copper, bismuth, and nickel. Copper nanoparticles (CuNPs) have fascinating properties such as the good thermal and electrical conductivity, nonlinear optical properties, and cost much less than the other metals. CuNPs are very well known for their potential application in cooling fluids for electronic systems, conductive inks, switches, or photochromic glasses in optical devices and nonlinear optical materials [146]. In addition, the CuNPs are widely used in electrochemistry as electrode materials. The effect of copper concentration and surfactants on the conductivity and stability of composite polymer-supported copper nanoparticles (CuNPs) were studied by Pham et al., and the nanoparticles with average diameter of $56 \mathrm{~nm}$ were synthesized by chemical reduction in the presence of cetyltrimethylammonium bromide (CTAB) and polyvinylpyrrolidone (PVP) as stabilizer. They have shown that these compounds prevent and protect the copper nanoparticles from the agglomeration and oxidation. The CuNPs were incorporated in PEDOT:PSS in aqueous solution to form conducting composite [147], who could be used for different applications. In situ chemical oxidation polymerization method was used to synthesis copper nanoparticles intercalated polyaniline nanocomposite. This nanocomposite was used to elaborate a sensor, which was applied for gas sensing towards different gases namely $\mathrm{NH}_{3}, \mathrm{CO}, \mathrm{CO}_{2}$, $\mathrm{NO}$, and $\mathrm{CH}_{4}$ at room temperature. The sensor films exhibited a highly selective response for $\mathrm{NH}_{3}$ with negligible response towards the other gases. Although the sensor have a drawback related to its sensitivity at high concentration, the saturation of the sensor was observed at concentration exceeding $50 \mathrm{ppm}$. The large surface area and charge transfer resulting of CuNPs intercalation in PANI matrix were the characteristics allowing the enhancement of the gas response [148]. The same method was used to synthesize nanocomposites of polypyrrole (PPy) containing copper sulfide $(\mathrm{CuS})$. The nanocomposite was characterized by the means of FTIR, scanning electron microscope, and X-ray diffraction, differential scanning calorimetry, confirming the formation 
of $\mathrm{CuS} / \mathrm{PPy}$ nanocomposites with porous, granular, and globular surface morphology and crystallinity. Besides, the thermal stability and the conductivity were also studies, indicating a better thermal stability. The dielectric behavior increases the order ness and the packing. Despite dielectric loss arises due to the localized motion of the charge carriers. The conductivity of CuS/PPy nanocomposite increases with the increase in the concentration of $\mathrm{CuS}$. The nanocomposites have a large scientific and technological interest and possible application like sensors [149]. Ternary $\mathrm{NiO} / \mathrm{CuO} /$ PANI nanocomposites were synthesized by in situ growth of $\mathrm{NiO} / \mathrm{CuO}$ nanoparticles via electrodeposition and electrochemical oxidation, in a PANI matrix prepared through electrodeposition. Due to the large surface area and good conductivity of $\mathrm{NiO} / \mathrm{CuO} / \mathrm{PANI}$ nanocomposite, a nonenzymatic sensor exhibited high electrocatalytic activity towards the oxidation of glucose. The modified electrode displayed higher sensitivity and a lower detection limit of $2.0 \mu \mathrm{M}[150] . \mathrm{MnO}_{x}$ nanoparticles have attracted large attention due to its abundance and relatively environmentally friendly nature [151]. To improve the capacitance property of PEDOT, Yang et al. used manganese dioxide nanoparticles $\mathrm{MnO}_{2}-\mathrm{NPs}$, to produce a high-performance electrochemical energy storage electrode. The PEDOT/ $\mathrm{MnO}_{2}-\mathrm{NPs}$ were prepared by simple thermal treatment and chemical vapor phase polymerization (VPP) methods. Despite the low conductivity and aggregation of $\mathrm{MnO}_{2}-\mathrm{NPs}$, the control of the loading and distribution of $\mathrm{MnO}_{2}-\mathrm{NPs}$ in PEDOT matrix offer uniform dispersion of nanoparticles into porous PEDOT matrix, which enhance the performance of the composite electrode [39]. The conductive PEDOT:PSS matrix was also used by Ju et al., with tin selenide SnSe nanosheets to achieve high-performance polymer-based thermoelectric devices. The subsequent solvent treatment appears a promising strategy to create the nanocomposites [152]. Other nanocomposites based on Gallium nitride nanoparticles $(\mathrm{GaN})$ and poly(3,4-ethylenedioxythiophene)-co-polypyrrole (GaN/PEDOT-PPY) were synthesized using supercritical ammonia method and by chemical oxidative polymerization method. The nanocomposite was used as an electrochemical catalyst for the oxidation of an antihelminthic drug mebendazole using differential pulse voltammetry [153]. Bismuth recognized with a low toxicity and widely used in electroanalytical as environmentally friendly electrode since the first publication of Wang et al., [154]. Bismuth nanoparticles were employed in synthesis of different nanocomposite materials for application in different area example power generation as thermoelectric material $[155,156]$ and electroanalysis as sensor. Polyaniline-bismuth oxide ( $\left.\mathrm{PANI}-\mathrm{Bi}_{2} \mathrm{O}_{3}\right)$ nanocomposite was used to fabricate a sensor for the detection of pramipexole in pharmaceutical formulation. The prepared electrode has lower charge transfer resistance leading to higher electrocatalytic activity. A highest concentration of PANI- $\mathrm{Bi}_{2} \mathrm{O}_{3}$ suspension causing thickness of the hybrid film and increasing concentration of surfactant leads to the increase of hydrophobicity of surfactant micelles that were decreased the performance of the sensor. The LOD and LOQ for the pramipexole detection are 1.10 and $3.35 \mu \mathrm{g} /$ $\mathrm{mL}$, respectively [157]. Salih et al. have modified carbon paste electrode (CPE) with poly(1,8-diaminonaphthalene) and bismuth film for detection of lead. The bi-poly1,8-DAN/ CPE was prepared and characterized by cyclic voltammetry and electrochemical impedance spectroscopy. It was demonstrated that higher concentration could cause the reduction of active sites on the surface of electrode. The modified electrode was applied for the analysis of lead in water samples using square wave voltammetry in acidic medium [158]. Similarly, Elbasri et al. have fabricated the modified poly(1,8-Diaminonaphthalene) by nickel ions particles (NiPs) on carbon paste electrode (CPE) for electrocatalytic oxidation of methanol in alkaline medium for direct methanol fuel cells (DMFCs). The obtained composite was characterized by scanning electron microscopy (SEM), cyclic voltammetry $(\mathrm{CV})$, and electrochemical impedance spectroscopy (EIS) [159]. Different metallic particles were used to develop a sensor for the electroanalysis of ascorbic acid (AA). Platinum electrode modified with polyterthiophene (P3T) and doped with metallic particles $(\mathrm{Cu}, \mathrm{Co}, \mathrm{Ag}, \mathrm{Au}$, and $\mathrm{Pd}$ ) was fabricated by first the electropolymerization of the monomer and then the incubation of the modified electrode in metallic ions solution to form the composite materials. The good sensitivity was obtained with the P3T-Ag film towards the target molecule AA, due to the high electron conductivity and good stability of the silver nanoparticles. The limit of detection was found to be $5.1710^{-10} \mathrm{~mol} \mathrm{~L}^{-1}$ using square wave voltammetry (SWV) [160].

The incorporation of metal nanoparticles with conducting polymers has led to a significant increase in the performance of devices in terms of sensitivity, selectivity, multiplexed detection capability, capacitance, and portability. In general, nanomaterials have played a key role in chemistry, biology, physics, engineering, and medicine. Table 2 shows the characteristics and the applications as sensors and fuel cells based on various nanostructured conducting polymers and nanoparticles.

\section{Challenges and trends}

The preparation, electrical characterization, and applications of composite layers formed by dispersing carbon on metallic nanostructures in polymer have been described. Indeed, the attractive properties of carbon structures such as carbon paste, carbon nanotube, carbon nanofibers, and graphene make them suitable materials for polymerizations of a number of monomers. The combination of carbon materials with polymers improves the properties of these materials 
Table 2 Nano-structured conducting polymer/nanoparticle-based sensors, biosensors, and other applications

\begin{tabular}{lll}
\hline Metal nanoparticles/conducting polymer & Application & Refs. \\
\hline Au/polyaniline & Dopamine & {$[118]$} \\
Au/polyaniline & $\mathrm{H}_{2} \mathrm{O}_{2}$ & {$[117]$} \\
Au/polyvinylpyrrolidone-polyaniline & Glucose & {$[124]$} \\
$\mathrm{Pt} /$ polypyrrole & C-reactive protein & {$[130]$} \\
$\mathrm{Pt} /$ poly(3,4-ethylenedioxythiophene):pol & Solar cells & {$[161]$} \\
y(styrenesulfonate) & & \\
Ag/polypyrrole & Hydrazine & {$[137]$} \\
Ag/polypyrrole & $\mathrm{H}_{2} \mathrm{O}_{2}$ & {$[136]$} \\
$\mathrm{Pd} /$ polyaniline & Fuel cells & {$[142]$} \\
Ni/poly(1,8-diaminonaphthalene) & Fuel cells & {$[159]$} \\
Au/poly(3,4ethylenedioxythiophene) & Cysteine & {$[162]$} \\
Au/poly(3,4-ethylenedioxythiophene) & Solar cells & {$[163]$} \\
Pd/poly(diphenylbutadiene) & Fuel cells & {$[164]$} \\
\hline
\end{tabular}

for different purposes (from electrochemical detection to fuel cell). From the work detailed in this review, it is clear also that the metallic nanoparticles such as gold, platinum, and silver combined with conducting polymers have much to offer in the different fields. However, to our best knowledge, no comparative study covering the electropolymerization of conducting polymer and carbon nanomaterial or metallic nanoparticles was reported. The fabrication of nanocomposites by chemical mode takes more time in all steps of preparation than electrochemical mode, either for nanoparticles synthesis or for polymerization. It could be take more than $48 \mathrm{~h}$ [165]. Furthermore, it was noted that the nanoparticles were generally synthesized by chemical ways which was more difficult compared to electrochemical one [166]. In addition to the use of many reagents, it requires a great deal of time and can spread out over long period [167]. In addition, all works mentioned that the modified electrode has good stability expressed by the responses of the electrodes found to be constant for the long term. The percentage of nanoparticles in the constitution of nanocomposites varies from one case to another. It was estimated to be between 0.1 and 20\% [168-170]. We have seen that the combination of conducting polymers and carbon nanomaterials or nanoparticles has led to better properties of these components [46, 171-173]. Metallic nanoparticles offer unique advantages when used for electroanalysis: enhancement of mass transport, catalysis, and high-effective surface area. The carbon nanostructures have attracted significant research activity due to their great potential application. Therefore, the question is: what will be the behavior of the nanocomposites if we combine NPs/polymers/CNMs? The formation of multicomponents nanocomposites was expected to improve their physical or chemical properties. Moreover, some advantageous properties were resulted by the fusion effects of these components including spectral, electronic, magnetic, optical properties, and specific surface area. Some interesting papers have been devoted to the strategies employed for the preparation of NPs/polymers/CNMs. As mentioned by recent papers, multi-component nanocomposites synthesized with the combination of $\mathrm{CNMs} / \mathrm{CPs}$ and MNPs produce new materials with exciting properties such as catalysis, enhancement of mass transport, high-effective surface area, and conductivity. Moreover, various strategies for the preparation of nanocomposites have been reported [166, 174-179]. In the light of recent works, it remains a challenge to founding new approaches to synthesize new nanocomposite materials based on carbon nanoparticles or metallic nanoparticles. The idea is to improve the simplicity and efficiency of the new composite and extend the application of the composite materials in different fields with a low cost.

Acknowledgements This work was supported by MESRSFC (Ministère de l'Enseignement Supérieur et de la Recherche Scientifique et de la Formation des cadres-Morocco) and CNRST (Centre National pour la Recherche Scientifique et Technique-Morocco) (Project number PPR/2015/72).

Open Access This article is distributed under the terms of the Creative Commons Attribution 4.0 International License (http://creativeco mmons.org/licenses/by/4.0/), which permits unrestricted use, distribution, and reproduction in any medium, provided you give appropriate credit to the original author(s) and the source, provide a link to the Creative Commons license, and indicate if changes were made.

\section{References}

1. MacDiarmid, A.G.: "Synthetic metals": a novel role for organic polymers (nobel lecture). Angew. Chem. Int. Ed. 40, 2581-2590 (2001). https://doi.org/10.1002/15213773(20010716)40:14<2581::aid-anie2581>3.0.co;2-2

2. Shirakawa, H., Louis, E.J., MacDiarmid, A.G., Chiang, C.K., Heeger, A.J.: Synthesis of electrically conducting organic polymers: halogen derivatives of polyacetylene, $(\mathrm{CH}) x$. J. Chem. Soc. Chem. Commun. (1977). https://doi.org/10.1039/c3977 0000578

3. Salih, F.E., Oularbi, L., Halim, E., Elbasri, M., Ouarzane, A., El Rhazi, M.: Conducting polymer/ionic liquid composite modified carbon paste electrode for the determination of carbaryl in real samples. Electroanalysis (2018). https://doi.org/10.1002/ elan.201800152

4. Chandrasekhar, P.: Conducting Polymers and Other New Electronically Conductive Materials Including Carbon Nanotubes and Graphene: Fundamentals and Applications. Springer, Berlin (2018)

5. Heeger, A.J.: Semiconducting and metallic polymers: the fourth generation of polymeric materials (nobel lecture). Angew. Chem. Int. Ed. 40, 2591-2611 (2001). https://doi.org/10.1002/15213773(20010716)40:14\%3c2591::aid-anie2591\%3e3.0.co;2-0

6. Tagmatarchis, N.: Advances in Carbon Nanomaterials: Science and Applications. CRC, Boca Raton (2012)

7. Navarro-Pardo, F., Martínez-Hernández, A.L., Velasco-Santos, C.: Polymer nanocomposites reinforced with functionalized 
carbon nanomaterials: nanodiamonds, carbon nanotubes and graphene. In: Mohanty, S., Nayak, S.K., Kaith, B.S., Kalia, S. (eds.) Polymer Nanocomposites Based on Inorganic and Organic Nanomaterials, pp. 347-399. Wiley, Oxford (2015)

8. Sattler, K.D.: Carbon Nanomaterials Sourcebook: Graphene, Nanotubes, and Nanodiamonds. CRC, Fullerenes (2016)

9. Kumar, S., Nehra, M., Kedia, D., Dilbaghi, N., Tankeshwar, K., Kim, K.-H.: Carbon nanotubes: a potential material for energy conversion and storage. Prog. Energy Combust. Sci. 64, 219-253 (2018). https://doi.org/10.1016/j.pecs.2017.10.005

10. Yu, X., Zhang, W., Zhang, P., Su, Z.: Fabrication technologies and sensing applications of graphene-based composite films: advances and challenges. Biosens. Bioelectron. 89, 72-84 (2017). https://doi.org/10.1016/j.bios.2016.01.081

11. Schrand, A.M.: Perspectives on Carbon Nanomaterials in Medicine Based upon Physicochemical Properties: Nanotubes, Nanodiamonds, and Carbon Nanobombs, pp. 3-29. Springer, Cham (2016). https://doi.org/10.1007/978-3-319-22861-7_1

12. Lee, D.H., Lee, J.A., Lee, W.J., Kim, S.O.: Flexible field emission of nitrogen-doped carbon nanotubes/reduced graphene hybrid films. Small 7, 95-100 (2011). https://doi.org/10.1002/ smll.201001168

13. Kong, L.B., Yan, W., Huang, Y., Que, W., Zhang, T., Li, S.: Carbon Nanomaterials Based on Carbon Nanotubes (CNTs), pp. 25-101. Springer, New Delhi (2016). https://doi. org/10.1007/978-81-322-2668-0_2

14. Zhang, F., Inganas, O., Zhou, Y., Vandewal, K.: Development of polymer-fullerene solar cells. Natl. Sci. Rev. 3, 222-239 (2016). https://doi.org/10.1093/nsr/nww020

15. Meer, S., Kausar, A., Iqbal, T.: Trends in conducting polymer and hybrids of conducting polymer/carbon nanotube: a review. Polym.-Plast. Technol. Eng. 55, 1416-1440 (2016). https://doi. org/10.1080/03602559.2016.1163601

16. Srikanth, V.V.S.S., Ramana, G.V., Kumar, P.S.: Perspectives on state-of-the-art carbon nanotube/polyaniline and graphene/ polyaniline composites for hybrid supercapacitor electrodes. J. Nanosci. Nanotechnol. 16, 2418-2424 (2016). https://doi. org/10.1166/jnn.2016.12471

17. Feng, L., Xie, N., Zhong, J.: Carbon nanofibers and their composites: a review of synthesizing, properties and applications. Materials 7, 3919-3945 (2014). https://doi.org/10.3390/ma705 3919

18. Oularbi, L., Turmine, M., Rhazi, M.E.: Electrochemical determination of traces lead ions using a new nanocomposite of polypyrrole/carbon nanofibers. J. Solid State Electrochem. 21, 3289-3300 (2017). https://doi.org/10.1007/s10008-017-3676-2

19. Li, X., Rao, M., Li, W.: Sulfur encapsulated in porous carbon nanospheres and coated with conductive polyaniline as cathode of lithium-sulfur battery. J. Solid State Electrochem. 20, 153161 (2015). https://doi.org/10.1007/s10008-015-3013-6

20. Zhang, P., Qiao, Z.A.: ChemInform abstract: recent advances in carbon nanospheres: synthetic routes and applications. Chem. Commun. (2015). https://doi.org/10.1039/c5cc01759a

21. Alvi, F., Ram, M.K., Basnayaka, P.A., Stefanakos, E., Goswami, Y., Kumar, A.: Graphene-polyethylenedioxythiophene conducting polymer nanocomposite based supercapacitor. Electrochim. Acta 56, 9406-9412 (2011). https://doi.org/10.1016/j.elect acta.2011.08.024

22. Mittal, G., Dhand, V., Rhee, K.Y., Park, S.-J., Lee, W.R.: A review on carbon nanotubes and graphene as fillers in reinforced polymer nanocomposites. J. Ind. Eng. Chem. 21, 11-25 (2015). https://doi.org/10.1016/j.jiec.2014.03.022

23. Zhang, J., Zhao, X.S.: Conducting polymers directly coated on reduced graphene oxide sheets as high-performance supercapacitor electrodes. J. Phys. Chem. C 116, 5420-5426 (2012). https:// doi.org/10.1021/jp211474e
24. Liu, Y., Kumar, S.: Polymer/carbon nanotube nano composite fibers-a review. ACS Appl. Mater. Interfaces. 6, 6069-6087 (2014). https://doi.org/10.1021/am405136s

25. Huang, L., Huang, Y., Liang, J., Wan, X., Chen, Y.: Graphenebased conducting inks for direct inkjet printing of flexible conductive patterns and their applications in electric circuits and chemical sensors. Nano Res. 4, 675-684 (2011). https://doi. org/10.1007/s12274-011-0123-z

26. Randriamahazaka, H., Ghilane, J.: Electrografting and controlled surface functionalization of carbon based surfaces for electroanalysis. Electroanalysis 28, 13-26 (2016). https://doi. org/10.1002/elan.201500527

27. Yang, N., Swain, G.M., Jiang, X.: Nanocarbon electrochemistry and electroanalysis: current status and future perspectives. Electroanalysis 28, 27-34 (2016). https://doi.org/10.1002/ elan.201500577

28. Li, M., Zhang, Y., Yang, L., Liu, Y., Ma, J.: Excellent electrochemical performance of homogeneous polypyrrole/graphene composites as electrode material for supercapacitors. J. Mater. Sci.: Mater. Electron. 26, 485-492 (2015). https://doi. org/10.1007/s10854-014-2425-x

29. Lota, K., Lota, G., Sierczynska, A., Acznik, I.: Carbon/ polypyrrole composites for electrochemical capacitors. Synth. Met. 203, 44-48 (2015). https://doi.org/10.1016/j.synth met.2015.02.014

30. Sekkarapatti Ramasamy, M., Nikolakapoulou, A., Raptis, D., Dracopoulos, V., Paterakis, G., Lianos, P.: Reduced graphene oxide/Polypyrrole/PEDOT composite films as efficient Pt-free counter electrode for dye-sensitized solar cells. Electrochim. Acta 173, 276-281 (2015). https://doi.org/10.1016/j.elect acta.2015.05.043

31. Gao, Y., Yip, H.-L., Chen, K.-S., O’Malley, K.M., Acton, O., Sun, Y., Ting, G., Chen, H., Jen, A.K.-Y.: Surface doping of conjugated polymers by graphene oxide and its application for organic electronic devices. Adv. Mater. 23, 1903-1908 (2011). https://doi.org/10.1002/adma.201100065

32. Holze, R., Wu, Y.P.: Intrinsically conducting polymers in electrochemical energy technology: trends and progress. Electrochim. Acta 122, 93-107 (2014). https://doi.org/10.1016/j.elect acta.2013.08.100

33. Jimena Monerris, M., D’Eramo, F., Javier Arevalo, F., Fernandez, H., Alicia Zon, M., Gabriela Molina, P.: Electrochemical immunosensor based on gold nanoparticles deposited on a conductive polymer to determine estrone in water samples. Microchem. J. 129, 71-77 (2016). https://doi.org/10.1016/j.microc.2016.06.001

34. Kondratiev, V.V., Malev, V.V., Eliseeva, S.N.: Composite electrode materials based on conducting polymers loaded with metal nanostructures. Russ. Chem. Rev. 85, 14 (2016). https://doi. org/10.1070/RCR4509

35. Zhu, R., Chung, C.-H., Cha, K.C., Yang, W., Zheng, Y.B., Zhou, H., Song, T.-B., Chen, C.-C., Weiss, P.S., Li, G., Yang, Y.: Fused silver nanowires with metal oxide nanoparticles and organic polymers for highly transparent conductors. ACS Nano 5, 9877-9882 (2011). https://doi.org/10.1021/nn203576v

36. Zou, H., Shang, M., Ren, G., Wang, W.: Polypyrrole-wrapped $\mathrm{Pd}$ nanoparticles hollow capsules as a catalyst for reduction of 4-nitroaniline. J. Appl. Polym. Sci. 133, 43933 (2016). https:// doi.org/10.1002/app.43933

37. Reznickova, A., Novotna, Z., Kvitek, O., Kolska, Z., Svorcik, V.: Gold, silver and carbon nanoparticles grafted on activated polymers for biomedical applications. J. Nanosci. Nanotechnol. 15, 10053-10073 (2015). https://doi.org/10.1166/jnn.2015.11689

38. Reznickova, A., Novotna, Z., Kolska, Z., Ulbrich, P., Svorcik, V.: Preparation, functionalization and grafting of noble metals nanoparticles to activated polymer. Chem. Listy 108, 865-874 (2014) 
39. Yang, Y., Yuan, W., Li, S., Yang, X., Xu, J., Jiang, Y.: Manganese dioxide nanoparticle enrichment in porous conducting polymer as high performance supercapacitor electrode materials. Electrochim. Acta 165, 323-329 (2015). https://doi.org/10.1016/j.elect acta.2015.03.052

40. Saleh, T.A., Gupta, V.K.: Synthesis, classification, and properties of nanomaterials. Nanomaterial and Polymer Membranes, pp. 83-133. Elsevier, New York (2016)

41. Reddy, K.R., Lee, K.-P., Lee, Y., Gopalan, A.I.: Facile synthesis of conducting polymer-metal hybrid nanocomposite by in situ chemical oxidative polymerization with negatively charged metal nanoparticles. Mater. Lett. 62, 1815-1818 (2008). https://doi.org/10.1016/j.matlet.2007.10.025

42. Park, J.-E., Atobe, M., Fuchigami, T.: Sonochemical synthesis of conducting polymer-metal nanoparticles nanocomposite. Electrochim. Acta 51, 849-854 (2005). https://doi. org/10.1016/j.electacta.2005.04.052

43. Bagheri, H., Banihashemi, S.: Sol-gel-based silver nanoparticles-doped silica-Polydiphenylamine nanocomposite for micro-solid-phase extraction. Anal. Chim. Acta 886, 56-65 (2015). https://doi.org/10.1016/j.aca.2015.06.012

44. Gniadek, M., Malinowska, S., Rapecki, T., Stojek, Z., Donten, M.: Synthesis of polymer-metal nanocomposites at liquidliquid interface supported by ultrasonic irradiation. Synth. Met. 187, 193-200 (2014). https://doi.org/10.1016/j.synth met.2013.10.031

45. Samu, G.F., Visy, C., Rajeshwar, K., Sarker, S., Subramanian, V.R., Janáky, C.: Photoelectrochemical infiltration of a conducting polymer (PEDOT) into metal-chalcogenide decorated $\mathrm{TiO}_{2}$ nanotube arrays. Electrochim. Acta 151, 467-476 (2015). https ://doi.org/10.1016/j.electacta.2014.11.094

46. Tang, C., Chen, N., Hu, X.: Conducting polymer nanocomposites: recent developments and future prospects. Conduct. Polym. Hybrids (2017). https://doi.org/10.1007/978-3-319-46458-9_1

47. Du, J., Cheng, H.-M.: The fabrication, properties, and uses of graphene/polymer composites. Macromol. Chem. Phys. 213, 1060-1077 (2012). https://doi.org/10.1002/macp.201200029

48. Sun, X., Sun, H., Li, H., Peng, H.: Developing polymer composite materials: carbon nanotubes or graphene? Adv. Mater. 25, 5153-5176 (2013). https://doi.org/10.1002/adma.201301926

49. Gupta, S., Price, C.: Investigating graphene/conducting polymer hybrid layered composites as pseudocapacitors: interplay of heterogeneous electron transfer, electric double layers and mechanical stability. Compos. Part B Eng. 105, 46-59 (2016). https://doi. org/10.1016/j.compositesb.2016.08.035

50. Huang, Y.Y., Terentjev, E.M.: Dispersion of carbon nanotubes: mixing, sonication, stabilization, and composite properties. Polymers. 4, 275-295 (2012). https://doi.org/10.3390/polym4010275

51. Kumar, S., Rath, T., Mahaling, R.N., Das, C.K.: Processing and characterization of carbon nanofiber/syndiotactic polystyrene composites in the absence and presence of liquid crystalline polymer. Compos. Part Appl. Sci. Manuf. 38, 1304-1317 (2007). https://doi.org/10.1016/j.compositesa.2006.11.006

52. Salavagione, H.J., Díez-Pascual, A.M., Lázaro, E., Vera, S., Gómez-Fatou, M.A.: Chemical sensors based on polymer composites with carbon nanotubes and graphene: the role of the polymer. J. Mater. Chem. A. 2, 14289-14328 (2014). https:// doi.org/10.1039/C4TA02159B

53. Rahman, M.M., Hussein, M.A., Alamry, K.A., Al Shehry, F.M., Asiri, A.M.: Sensitive methanol sensor based on PMMA-GCNTs nanocomposites deposited onto glassy carbon electrodes. Talanta 150, 71-80 (2016). https://doi.org/10.1016/j.talan ta.2015.12.012

54. Kaur, N., Thakur, H., Prabhakar, N.: Conducting polymer and multi-walled carbon nanotubes nanocomposites based amperometric biosensor for detection of organophosphate. J. Electroanal.
Chem. 775, 121-128 (2016). https://doi.org/10.1016/j.jelec hem.2016.05.037

55. Yan, J., Wang, Q., Wei, T., Fan, Z.: Recent advances in design and fabrication of electrochemical supercapacitors with high energy densities. Adv. Energy Mater. (2014). https://doi. org/10.1002/aenm.201300816

56. Peng, C., Zhang, S., Jewell, D., Chen, G.Z.: Carbon nanotube and conducting polymer composites for supercapacitors. Prog. Nat. Sci. 18, 777-788 (2008). https://doi.org/10.1016/j. pnsc.2008.03.002

57. Shown, I., Ganguly, A., Chen, L.-C., Chen, K.-H.: Conducting polymer-based flexible supercapacitor. Energy Sci. Eng. 3, 2-26 (2015). https://doi.org/10.1002/ese3.50

58. Li, J., Cheng, X., Shashurin, A., Keidar, M.: Review of electrochemical capacitors based on carbon nanotubes and graphene. Graphene 01, 1 (2012). https://doi.org/10.4236/graph ene.2012.11001

59. Spitalsky, Z., Tasis, D., Papagelis, K., Galiotis, C.: Carbon nanotube-polymer composites: chemistry, processing, mechanical and electrical properties. Prog. Polym. Sci. 35, 357-401 (2010). https ://doi.org/10.1016/j.progpolymsci.2009.09.003

60. Patil, P., Gaikwad, G., Patil, D.R., Naik, J.: Gas sensitivity study of polypyrrole decorated graphene oxide thick film. J. Inst. Eng. India Ser. D. 97, 47-53 (2016). https://doi.org/10.1007/s4003 3-015-0085-5

61. Gu, Z., Li, C., Wang, G., Zhang, L., Li, X., Wang, W., Jin, S.: Synthesis and characterization of polypyrrole/graphite oxide composite by in situ emulsion polymerization. J. Polym. Sci. Part B Polym. Phys. 48, 1329-1335 (2010). https://doi.org/10.1002/ polb.22031

62. Mangu, R., Rajaputra, S., Singh, V.P.: MWCNT-polymer composites as highly sensitive and selective room temperature gas sensors. Nanotechnology 22, 215502 (2011). https://doi. org/10.1088/0957-4484/22/21/215502

63. Sun, S., Zhang, M., Li, Y., He, X.: A molecularly imprinted polymer with incorporated graphene oxide for electrochemical determination of quercetin. Sensors 13, 5493-5506 (2013). https ://doi.org/10.3390/s130505493

64. Zhuang, Z., Li, J.: Electrochemical detection of dopamine in the presence of ascorbic acid using overoxidized polypyrrole/ graphene modified electrodes. Int. J. Electrochem. Sci. 6, 2149$2161(2011)$

65. Elbasri, M., Majid, S., Lafdi, K., El Rhazi, M.: Highly improved electrocatalytic oxidation of methanol on poly (1, 5-diaminonaphthalene)/nickel nanoparticles film modified carbon nanofiber. J. Mater. Environ. Sci. 7, 2860-2869 (2017)

66. Xu, G., Li, B., Cui, X.T., Ling, L., Luo, X.: Electrodeposited conducting polymer PEDOT doped with pure carbon nanotubes for the detection of dopamine in the presence of ascorbic acid. Sens. Actuators B Chem. 188, 405-410 (2013). https://doi. org/10.1016/j.snb.2013.07.038

67. Zhu, C., Zhai, J., Wen, D., Dong, S.: Graphene oxide/polypyrrole nanocomposites: one-step electrochemical doping, coating and synergistic effect for energy storage. J. Mater. Chem. 22, 6300-6306 (2012). https://doi.org/10.1039/C2JM16699B

68. Luo, X., Weaver, C.L., Tan, S., Cui, X.T.: Pure graphene oxide doped conducting polymer nanocomposite for bio-interfacing. J. Mater. Chem. B. 1, 1340-1348 (2013). https://doi.org/10.1039/ C3TB00006K

69. Liu, D., Wang, X., Deng, J., Zhou, C., Guo, J., Liu, P.: Crosslinked carbon nanotubes/polyaniline composites as a pseudocapacitive material with high cycling stability. Nanomaterials 5, 1034-1047 (2015). https://doi.org/10.3390/nano5021034

70. Gui, D., Liu, C., Chen, F., Liu, J.: Preparation of polyaniline/graphene oxide nanocomposite for the application of supercapacitor. 
Appl. Surf. Sci. 307, 172-177 (2014). https://doi.org/10.1016/j. apsusc.2014.04.007

71. Iijima, S.: Helical microtubules of graphitic carbon. Nature 354, 56-58 (1991)

72. Oueiny, C., Berlioz, S., Perrin, F.-X.: Carbon nanotube-polyaniline composites. Prog. Polym. Sci. 39, 707-748 (2014). https:// doi.org/10.1016/j.progpolymsci.2013.08.009

73. Suckeveriene, R.Y., Zelikman, E., Mechrez, G., Narkis, M.: Literature review: conducting carbon nanotube/polyaniline nanocomposites. Rev. Chem. Eng. 27, 15-21 (2011). https:// doi.org/10.1515/revce.2011.004

74. Sharma, S., Hussain, S., Singh, S., Islam, S.S.: MWCNTconducting polymer composite based ammonia gas sensors: a new approach for complete recovery process. Sens. Actuators B Chem. 194, 213-219 (2014). https://doi.org/10.1016/j. snb.2013.12.050

75. Zhou, H., Han, G., Xiao, Y., Chang, Y., Zhai, H.-J.: A comparative study on long and short carbon nanotubes-incorporated polypyrrole/poly(sodium 4-styrenesulfonate) nanocomposites as high-performance supercapacitor electrodes. Synth. Met. 209, 405-411 (2015). https://doi.org/10.1016/j.synth met.2015.08.014

76. Sadrolhosseini, A.R., Noor, A.S.M., Bahrami, A., Lim, H.N., Talib, Z.A., Mahdi, M.A.: Application of polypyrrole multiwalled carbon nanotube composite layer for detection of mercury, lead and iron ions using surface plasmon resonance technique. PLoS One 9, e93962 (2014). https://doi.org/10.1371/journ al.pone.0093962

77. Bachhav, S.G., Patil, D.R.: Study of polypyrrole-coated MWCNT nanocomposites for ammonia sensing at room temperature. J. Mater. Sci. Chem. Eng. 03, 30 (2015). https://doi.org/10.4236/ msce.2015.310005

78. Barsan, M.M., Ghica, M.E., Brett, C.M.A.: Electrochemical sensors and biosensors based on redox polymer/carbon nanotube modified electrodes: a review. Anal. Chim. Acta 881, 1-23 (2015). https://doi.org/10.1016/j.aca.2015.02.059

79. Kovtyukhova, N.I., Ollivier, P.J., Martin, B.R., Mallouk, T.E., Chizhik, S.A., Buzaneva, E.V., Gorchinskiy, A.D.: Layer-bylayer assembly of ultrathin composite films from micron-sized graphite oxide sheets and polycations. Chem. Mater. 11, 771-778 (1999). https://doi.org/10.1021/cm981085u

80. Kim, M., Lee, C., Seo, Y.D., Cho, S., Kim, J., Lee, G., Kim, Y.K., Jang, J.: Fabrication of various conducting polymers using graphene oxide as a chemical oxidant. Chem. Mater. 27, 6238-6248 (2015). https://doi.org/10.1021/acs.chemmater.5b01408

81. Ambrosi, A., Bonanni, A., Sofer, Z., Cross, J.S., Pumera, M.: Electrochemistry at chemically modified graphenes. Chem. Eur. J. 17, 10763-10770 (2011). https://doi.org/10.1002/chem.20110 1117

82. Zhu, Y., Murali, S., Cai, W., Li, X., Suk, J.W., Potts, J.R., Ruoff, R.S.: Graphene and graphene oxide: synthesis, properties, and applications. Adv. Mater. 22, 3906-3924 (2010). https://doi. org/10.1002/adma.201001068

83. Allen, M.J., Tung, V.C., Kaner, R.B.: Honeycomb carbon: a review of graphene. Chem. Rev. 110, 132-145 (2010). https:// doi.org/10.1021/cr900070d

84. Dreyer, D.R., Park, S., Bielawski, C.W., Ruoff, R.S.: The chemistry of graphene oxide. Chem. Soc. Rev. 39, 228-240 (2010). https://doi.org/10.1039/b917103g

85. Ambrosi, A., Pumera, M.: Precise tuning of surface composition and electron-transfer properties of graphene oxide films through electroreduction. Chem. Eur. J. 19, 4748-4753 (2013). https:// doi.org/10.1002/chem.201204226

86. Wang, W., Xu, G., Cui, X.T., Sheng, G., Luo, X.: Enhanced catalytic and dopamine sensing properties of electrochemically reduced conducting polymer nanocomposite doped with pure graphene oxide. Biosens. Bioelectron. 58, 153-156 (2014). https ://doi.org/10.1016/j.bios.2014.02.055

87. Seekaew, Y., Lokavee, S., Phokharatkul, D., Wisitsoraat, A., Kerdcharoen, T., Wongchoosuk, C.: Low-cost and flexible printed graphene-PEDOT:PSS gas sensor for ammonia detection. Org. Electron. 15, 2971-2981 (2014). https://doi. org/10.1016/j.orgel.2014.08.044

88. Li, X., Liang, L., Yang, M., Chen, G., Guo, C.-Y.: Poly(3,4ethylenedioxythiophene)/graphene/carbon nanotube ternary composites with improved thermoelectric performance. Org. Electron. 38, 200-204 (2016). https://doi.org/10.1016/j.orgel .2016.08.022

89. Bora, C., Dolui, S.K.: Fabrication of polypyrrole/graphene oxide nanocomposites by liquid/liquid interfacial polymerization and evaluation of their optical, electrical and electrochemical properties. Polymer 53, 923-932 (2012). https://doi. org/10.1016/j.polymer.2011.12.054

90. Zuo, X., Zhang, Y., Si, L., Zhou, B., Zhao, B., Zhu, L., Jiang, $X .:$ One-step electrochemical preparation of sulfonated graphene/polypyrrole composite and its application to supercapacitor. J. Alloys Compd. Part B 688, 140-148 (2016). https:// doi.org/10.1016/j.jallcom.2016.07.184

91. Rong, R., Zhao, H., Gan, X., Chen, S., Quan, X.: An electrochemical sensor based on graphene-polypyrrole nanocomposite for the specific detection of $\mathrm{Pb}(\mathrm{II})$. Nano 12, 1750008 (2016). https://doi.org/10.1142/S1793292017500084

92. Elnaggar, E.M., Kabel, K.I., Farag, A.A., Al-Gamal, A.G.: Comparative study on doping of polyaniline with graphene and multi-walled carbon nanotubes. J. Nanostruct. Chem. 7, 75-83 (2017). https://doi.org/10.1007/s40097-017-0217-6

93. Yang, Y., Kang, M., Fang, S., Wang, M., He, L., Zhao, J., Zhang, H., Zhang, Z.: Electrochemical biosensor based on three-dimensional reduced graphene oxide and polyaniline nanocomposite for selective detection of mercury ions. Sens. Actuators B Chem. 214, 63-69 (2015). https://doi. org/10.1016/j.snb.2015.02.127

94. Nguyen, V.H., Lamiel, C., Kharismadewi, D., Tran, V.C., Shim, J.-J.: Covalently bonded reduced graphene oxide/polyaniline composite for electrochemical sensors and capacitors. J. Electroanal. Chem. 758, 148-155 (2015). https://doi.org/10.1016/j. jelechem.2015.10.023

95. Ruecha, N., Rodthongkum, N., Cate, D.M., Volckens, J., Chailapakul, O., Henry, C.S.: Sensitive electrochemical sensor using a graphene-polyaniline nanocomposite for simultaneous detection of $\mathrm{Zn}(\mathrm{II}), \mathrm{Cd}(\mathrm{II})$, and $\mathrm{Pb}(\mathrm{II})$. Anal. Chim. Acta 874, 40-48 (2015). https://doi.org/10.1016/j.aca.2015.02.064

96. Promphet, N., Rattanarat, P., Rangkupan, R., Chailapakul, O., Rodthongkum, N.: An electrochemical sensor based on graphene/polyaniline/polystyrene nanoporous fibers modified electrode for simultaneous determination of lead and cadmium. Sens. Actuators B Chem. Part A 207, 526-534 (2015). https:// doi.org/10.1016/j.snb.2014.10.126

97. Nguyen, T.D., Dang, T.T.H., Thai, H., Nguyen, L.H., Tran, D.L., Piro, B., Pham, M.C.: One-step electrosynthesis of poly(1,5diaminonaphthalene)/graphene nanocomposite as platform for lead detection in water. Electroanalysis 28, 1907-1913 (2016). https://doi.org/10.1002/elan.201501075

98. Mallya, A.N., Kottokkaran, R., Ramamurthy, P.C.: Conducting polymer-carbon black nanocomposite sensor for volatile organic compounds and correlating sensor response by molecular dynamics. Sens. Actuators B Chem. 201, 308-320 (2014). https://doi. org/10.1016/j.snb.2014.04.056

99. Calisi, N., Giuliani, A., Alderighi, M., Schnorr, J.M., Swager, T.M., Di Francesco, F., Pucci, A.: Factors affecting the dispersion of MWCNTs in electrically conducting SEBS nanocomposites. 
Eur. Polym. J. 49, 1471-1478 (2013). https://doi.org/10.1016/j. eurpolymj.2013.03.029

100. Luo, Y.-L., Wei, X.-P., Cao, D., Bai, R.-X., Xu, F., Chen, Y.-S.: Polystyrene-block-poly(tert-butyl methacrylate)/multiwall carbon nanotube ternary conducting polymer nanocomposites based on compatibilizers: preparation, characterization and vapor sensing applications. Mater. Des. 87, 149-156 (2015). https://doi. org/10.1016/j.matdes.2015.08.030

101. Luzi-Thafeni, L., Silwana, B., Iwuoh, E., Somerset, V.: Graphene-polyaniline biosensor for carbamate pesticide determination in fruit samples. Biosens. Micro Nanoscale Appl. (2015). https://doi.org/10.5772/61220

102. Zuo, Y., Xu, J., Zhu, X., Duan, X., Lu, L., Gao, Y., Xing, H., Yang, T., Ye, G., Yu, Y.: Poly(3,4-ethylenedioxythiophene) nanorods/graphene oxide nanocomposite as a new electrode material for the selective electrochemical detection of mercury (II). Synth. Met. 220, 14-19 (2016). https://doi.org/10.1016/j. synthmet.2016.05.022

103. Raj, M., Gupta, P., Goyal, R.N., Shim, Y.-B.: Graphene/conducting polymer nano-composite loaded screen printed carbon sensor for simultaneous determination of dopamine and 5-hydroxytryptamine. Sens. Actuators B Chem. 239, 993-1002 (2017). https://doi.org/10.1016/j.snb.2016.08.083

104. Sih, B.C., Wolf, M.O.: Metal nanoparticle-conjugated polymer nanocomposites. Chem. Commun. (2005). https://doi. org/10.1039/B501448D

105. Zare, Y., Shabani, I.: Polymer/metal nanocomposites for biomedical applications. Mater. Sci. Eng., C 60, 195-203 (2016). https://doi.org/10.1016/j.msec.2015.11.023

106. Tamayo, L., Azócar, M., Kogan, M., Riveros, A., Páez, M.: Copper-polymer nanocomposites: an excellent and costeffective biocide for use on antibacterial surfaces. Mater. Sci. Eng. C 69, 1391-1409 (2016). https://doi.org/10.1016/j. msec.2016.08.041

107. Jia, C.-J., Schüth, F.: Colloidal metal nanoparticles as a component of designed catalyst. Phys. Chem. Chem. Phys. 13, 24572487 (2011). https://doi.org/10.1039/C0CP02680H

108. Adlim, A.: Preparations and application of metal nanoparticles. Indones. J. Chem. 6, 1-10 (2010)

109. Wang, H.-H., Zhang, B., Li, X.-H., Antonietti, M., Chen, J.-S.: Activating Pd nanoparticles on sol-gel prepared porous g-C3N4/ $\mathrm{SiO} 2$ via enlarging the Schottky barrier for efficient dehydrogenation of formic acid. Inorg. Chem. Front. 3, 1124-1129 (2016). https://doi.org/10.1039/C6QI00151C

110. Nadagouda, M.N., Speth, T.F., Varma, R.S.: Microwave-assisted green synthesis of silver nanostructures. Acc. Chem. Res. 44, 469-478 (2011). https://doi.org/10.1021/ar1001457

111. Park, H., Reddy, D.A., Kim, Y., Lee, S., Ma, R., Kim, T.K.: Synthesis of ultra-small Pd nanoparticles deposited on CdS nanorods by pulsed laser ablation in liquid: role of metal nanocrystal size in the photocatalytic hydrogen production. Eur. J, Chem (2017). https://doi.org/10.1002/chem.201702304

112. Lu, X., Zhang, W., Wang, C., Wen, T.-C., Wei, Y.: One-dimensional conducting polymer nanocomposites: synthesis, properties and applications. Prog. Polym. Sci. 36, 671-712 (2011). https:// doi.org/10.1016/j.progpolymsci.2010.07.010

113. Muñoz-Bonilla, A., Sánchez-Marcos, J., Herrasti, P.: Magnetic nanoparticles-based conducting polymer nanocomposites. Conducting Polymer Hybrids, pp. 45-80. Springer, Cham (2017)

114. Li, M., Wang, W., Chen, Z., Song, Z., Luo, X.: Electrochemical determination of paracetamol based on Au@graphene core-shell nanoparticles doped conducting polymer PEDOT nanocomposite. Sens. Actuators B Chem. 260, 778-785 (2018). https://doi. org/10.1016/j.snb.2018.01.093

115. Gopalan, S.-A., Gopalan, A.-I., Vinu, A., Lee, K.-P., Kang, S.-W.: A new optical-electrical integrated buffer layer design based on gold nanoparticles tethered thiol containing sulfonated polyaniline towards enhancement of solar cell performance. Sol. Energy Mater. Sol. Cells 174, 112-123 (2018). https://doi.org/10.1016/j. solmat.2017.08.029

116. Liu, D., Wang, H., Du, P., Wei, W., Wang, Q., Liu, P.: Flexible and robust reduced graphene oxide/carbon nanoparticles/ polyaniline (RGO/CNs/PANI) composite films: excellent candidates as free-standing electrodes for high-performance supercapacitors. Electrochim. Acta 259, 161-169 (2018). https://doi. org/10.1016/j.electacta.2017.10.165

117. Hung, C.-C., Wen, T.-C., Wei, Y.: Site-selective deposition of ultra-fine Au nanoparticles on polyaniline nanofibers for $\mathrm{H} 2 \mathrm{O} 2$ sensing. Mater. Chem. Phys. 122, 392-396 (2010). https://doi. org/10.1016/j.matchemphys.2010.03.012

118. Huang, K.-J., Zhang, J.-Z., Liu, Y.-J., Wang, L.-L.: Novel electrochemical sensing platform based on molybdenum disulfide nanosheets-polyaniline composites and Au nanoparticles. Sens. Actuators B Chem. 194, 303-310 (2014). https://doi. org/10.1016/j.snb.2013.12.106

119. Zhang, J., Liu, X., Wu, S., Xu, H., Cao, B.: One-pot fabrication of uniform polypyrrole/Au nanocomposites and investigation for gas sensing. Sens. Actuators B Chem. 186, 695-700 (2013). https ://doi.org/10.1016/j.snb.2013.06.063

120. Zhang, J., Wang, C., Niu, Y., Li, S., Luo, R.: Electrochemical sensor based on molecularly imprinted composite membrane of $\operatorname{poly}(o$-aminothiophenol) with gold nanoparticles for sensitive determination of herbicide simazine in environmental samples. Sens. Actuators B Chem (2017). https://doi.org/10.1016/j. snb.2016.02.068

121. Blanco-Loimil, M., Pardo, A., Villar-Alvarez, E., MartínezGonzález, R., Topete, A., Barbosa, S., Taboada, P., Mosquera, V.: Development of ordered metal nanoparticle arrangements on solid supports by combining a green nanoparticle synthetic method and polymer templating for sensing applications. RSC Adv. 6, 60502-60512 (2016). https://doi.org/10.1039/C6RA0 $4925 \mathrm{G}$

122. Rezaei, B., Boroujeni, M.K., Ensafi, A.A.: Fabrication of DNA, o-phenylenediamine, and gold nanoparticle bioimprinted polymer electrochemical sensor for the determination of dopamine. Biosens. Bioelectron. 66, 490-496 (2015). https://doi. org/10.1016/j.bios.2014.12.009

123. Sundaramurthy, J., Dharmarajan, R., Srinivasan, M.P.: Fabrication of molecular hybrid films of gold nanoparticle and polythiophene by covalent assembly. Thin Solid Films 589, 238-245 (2015). https://doi.org/10.1016/j.tsf.2015.05.031

124. Miao, Z., Wang, P., Zhong, A., Yang, M., Xu, Q., Hao, S., Hu, X.: Development of a glucose biosensor based on electrodeposited gold nanoparticles-polyvinylpyrrolidone-polyaniline nanocomposites. J. Electroanal. Chem. 756, 153-160 (2015). https://doi. org/10.1016/j.jelechem.2015.08.025

125. Kesik, M., Kanik, F.E., Hizalan, G., Kozanoglu, D., Esenturk, E.N., Timur, S., Toppare, L.: A functional immobilization matrix based on a conducting polymer and functionalized gold nanoparticles: synthesis and its application as an amperometric glucose biosensor. Polymer 54, 4463-4471 (2013). https://doi. org/10.1016/j.polymer.2013.06.050

126. El-Said, W.A., Choi, J.-W.: Electrochemical Biosensor consisted of conducting polymer layer on gold nanodots patterned Indium Tin Oxide electrode for rapid and simultaneous determination of purine bases. Electrochim. Acta 123, 51-57 (2014). https://doi. org/10.1016/j.electacta.2013.12.144

127. Lin, P., Chai, F., Zhang, R., Xu, G., Fan, X., Luo, X.: Electrochemical synthesis of poly(3,4-ethylenedioxythiophene) doped with gold nanoparticles, and its application to nitrite sensing. Microchim. Acta 183, 1235-1241 (2016). https://doi. org/10.1007/s00604-016-1751-5 
128. Sadanandhan, N.K., Devaki, S.J.: Gold nanoparticle patterned on PANI nanowire modified transducer for the simultaneous determination of neurotransmitters in presence of ascorbic acid and uric acid. J. Appl. Polym. Sci. (2017). https://doi.org/10.1002/ app. 44351

129. Lemos, H.G., Santos, S.F., Venancio, E.C.: Polyaniline-Pt and polypyrrole-Pt nanocomposites: effect of supporting type and morphology on the nanoparticles size and distribution. Synth. Met. 203, 22-30 (2015). https://doi.org/10.1016/j.synth met.2015.02.006

130. Mishra, S.K., Srivastava, A.K., Kumar, D., Mulchandani, A.: Protein functionalized Pt nanoparticles-conducting polymer nanocomposite film: characterization and immunosensor application. Polymer 55, 4003-4011 (2014). https://doi.org/10.1016/j. polymer.2014.05.061

131. Adeloju, S.B., Hussain, S.: Potentiometric sulfite biosensor based on entrapment of sulfite oxidase in a polypyrrole film on a platinum electrode modified with platinum nanoparticles. Microchim. Acta 183, 1341-1350 (2016). https://doi.org/10.1007/s0060 4-016-1748-0

132. Boomi, P., Prabu, H.G., Mathiyarasu, J.: Synthesis, characterization and antibacterial activity of polyaniline/Pt-Pd nanocomposite. Eur. J. Med. Chem. 72, 18-25 (2014). https://doi. org/10.1016/j.ejmech.2013.09.049

133. Zhai, D., Liu, B., Shi, Y., Pan, L., Wang, Y., Li, W., Zhang, R., Yu, G.: Highly sensitive glucose sensor based on Pt nanoparticle/ polyaniline hydrogel heterostructures. ACS Nano 7, 3540-3546 (2013). https://doi.org/10.1021/nn400482d

134. Stejskal, J.: Conducting polymer-silver composites. Chem. Pap. 67, 814-848 (2013). https://doi.org/10.2478/s11696-012-0304-6

135. Abbasi, N.M., Yu, H., Wang, L., Zain-ul-Abdin, W.A., Akram, M., Khalid, H., Chen, Y., Saleem, M., Sun, R., Shan, J.: Preparation of silver nanowires and their application in conducting polymer nanocomposites. Mater. Chem. Phys. 166, 1-15 (2015). https://doi.org/10.1016/j.matchemphys.2015.08.056

136. Nia, P.M., Meng, W.P., Alias, Y.: Hydrogen peroxide sensor: Uniformly decorated silver nanoparticles on polypyrrole for wide detection range. Appl. Surf. Sci. Part B 357, 1565-1572 (2015). https://doi.org/10.1016/j.apsusc.2015.10.026

137. Ghanbari, K.: Fabrication of silver nanoparticles-polypyrrole composite modified electrode for electrocatalytic oxidation of hydrazine. Synth. Met. 195, 234-240 (2014). https://doi. org/10.1016/j.synthmet.2014.06.014

138. Alam, M.F., Laskar, A.A., Zubair, M., Baig, U., Younus, H.: Immobilization of yeast alcohol dehydrogenase on polyaniline coated silver nanoparticles formed by green synthesis. J. Mol. Catal. B Enzym. 119, 78-84 (2015). https://doi.org/10.1016/j. molcatb.2015.06.004

139. Zang, L., Qiu, J., Yang, C., Sakai, E.: Preparation and application of conducting polymer/Ag/clay composite nanoparticles formed by in situ UV-induced dispersion polymerization. Sci. Rep. (2016). https://doi.org/10.1038/srep20470

140. Bhadra, J., Al-Thani, N.J., Karmakar, S., Madi, N.K.: Photoreduced route of polyaniline nanofiber synthesis with embedded silver nanoparticles. Arab. J. Chem. (2016). https://doi. org/10.1016/j.arabjc.2016.10.001

141. Wang, J., Gu, H.: Novel metal nanomaterials and their catalytic applications. Molecules 20, 17070-17092 (2015). https://doi. org/10.3390/molecules200917070

142. Prodromidis, M.I., Zahran, E.M., Tzakos, A.G., Bachas, L.G.: Preorganized composite material of polyaniline-palladium nanoparticles with high electrocatalytic activity to methanol and ethanol oxidation. Int. J. Hydrog. Energy. 40, 6745-6753 (2015). https://doi.org/10.1016/j.ijhydene.2015.03.102

143. Li, H., Chen, G., Duchesne, P.N., Zhang, P., Dai, Y., Yang, H., Wu, B., Liu, S., Xu, C., Zheng, N.: A nanoparticulate polyacetylene-supported $\mathrm{Pd}(\mathrm{II})$ catalyst combining the advantages of homogeneous and heterogeneous catalysts. Chin. J. Catal. 36, 1560-1572 (2015). https://doi.org/10.1016/S1872 -2067(15)60930-5

144. Sapurina, I., Stejskal, J., Šeděnková, I., Trchová, M., Kovářová, J., Hromádková, J., Kopecká, J., Cieslar, M., Abu El-Nasr, A., Ayad, M.M.: Catalytic activity of polypyrrole nanotubes decorated with noble-metal nanoparticles and their conversion to carbonized analogues. Synth. Met. 214, 14-22 (2016). https:// doi.org/10.1016/j.synthmet.2016.01.009

145. Hosseini, H., Rezaei, S.J.T., Rahmani, P., Sharifi, R., Nabid, M.R., Bagheri, A.: Nonenzymatic glucose and hydrogen peroxide sensors based on catalytic properties of palladium nanoparticles/poly(3,4-ethylenedioxythiophene) nanofibers. Sens. Actuators B Chem. 195, 85-91 (2014). https://doi.org/10.1016/j. snb.2014.01.015

146. Dang, T.M.D., Le, T.T.T., Fribourg-Blanc, E., Dang, M.C.: Synthesis and optical properties of copper nanoparticles prepared by a chemical reduction method. Adv. Nat. Sci. Nanosci. Nanotechnol. 2, 015009 (2011). https://doi.org/10.1088/20436262/2/1/015009

147. Pham, L.Q., Sohn, J.H., Kim, C.W., Park, J.H., Kang, H.S., Lee, B.C., Kang, Y.S.: Copper nanoparticles incorporated with conducting polymer: effects of copper concentration and surfactants on the stability and conductivity. J. Colloid Interface Sci. 365, 103-109 (2012). https://doi.org/10.1016/j.jcis.2011.09.041

148. Patil, U.V., Ramgir, N.S., Karmakar, N., Bhogale, A., Debnath, A.K., Aswal, D.K., Gupta, S.K., Kothari, D.C.: Room temperature ammonia sensor based on copper nanoparticle intercalated polyaniline nanocomposite thin films. Appl. Surf. Sci. 339, 69-74 (2015). https://doi.org/10.1016/j.apsusc.2015.02.164

149. Ramesan, M.T.: Synthesis, characterization, and conductivity studies of polypyrrole/copper sulfide nanocomposites. J. Appl. Polym. Sci. (2012). https://doi.org/10.1002/app.38304

150. Ghanbari, K., Babaei, Z.: Fabrication and characterization of non-enzymatic glucose sensor based on ternary $\mathrm{NiO} / \mathrm{CuO} /$ polyaniline nanocomposite. Anal. Biochem. 498, 37-46 (2016). https ://doi.org/10.1016/j.ab.2016.01.006

151. Sabo, D.E.: Novel synthesis of metal oxide nanoparticles via the aminolytic method and the investigation of their magnetic properties. (2012)

152. Ju, H., Kim, J.: Fabrication of conductive polymer/inorganic nanoparticles composite films: PEDOT:PSS with exfoliated tin selenide nanosheets for polymer-based thermoelectric devices. Chem. Eng. J. 297, 66-73 (2016). https://doi.org/10.1016/j. cej.2016.03.137

153. Munusamy, S., Suresh, R., Giribabu, K., Manigandan, R., Praveen Kumar, S., Muthamizh, S., Bagavath, C., Stephen, A., Kumar, J., Narayanan, V.: Synthesis and characterization of GaN/ PEDOT-PPY nanocomposites and its photocatalytic activity and electrochemical detection of mebendazole. Arab. J. Chem. (2012). https://doi.org/10.1016/j.arabjc.2015.10.012

154. Wang, J., Lu, J., Hocevar, S.B., Farias, P.A.M., Ogorevc, B.: Bismuth-coated carbon electrodes for anodic stripping voltammetry. Anal. Chem. 72, 3218-3222 (2000). https://doi.org/10.1021/ ac000108x

155. Chatterjee, K., Suresh, A., Ganguly, S., Kargupta, K., Banerjee, D.: Synthesis and characterization of an electro-deposited polyaniline-bismuth telluride nanocomposite-A novel thermoelectric material. Mater. Char. 60, 1597-1601 (2009). https://doi. org/10.1016/j.matchar.2009.09.012

156. Toshima, N., Imai, M., Ichikawa, S.: Organic-inorganic nanohybrids as novel thermoelectric materials: hybrids of polyaniline and bismuth(III) telluride nanoparticles. J. Electron. Mater. 40, 898-902 (2011). https://doi.org/10.1007/s11664-010-1403-1 
157. Jain, R., Tiwari, D.C., Shrivastava, S.: Polyaniline-bismuth oxide nanocomposite sensor for quantification of anti-parkinson drug pramipexole in solubilized system. Mater. Sci. Eng., B 185, 53-59 (2014). https://doi.org/10.1016/j.mseb.2014.02.007

158. Salih, F.E., Ouarzane, A., El Rhazi, M.: Electrochemical detection of lead (II) at bismuth/Poly(1,8-diaminonaphthalene) modified carbon paste electrode. Arab. J. Chem. 10, 596-603 (2017). https://doi.org/10.1016/j.arabjc.2015.08.021

159. Elbasri, M., Rhazi, M.E.: Preparation and characterization of carbon paste electrode modified by poly(1,8-diaminonaphthalene) and nickel ions particles: application to electrocatalytic oxidation of methanol. Mater. Today Proc. 2, 4676-4683 (2015). https:// doi.org/10.1016/j.matpr.2015.09.022

160. Maouche, N., Nessark, B., Bakas, I.: Platinum electrode modified with polyterthiophene doped with metallic nanoparticles, as sensitive sensor for the electroanalysis of ascorbic acid (AA). Arab. J. Chem. (2015). https://doi.org/10.1016/j.arabjc.2015.04.029

161. Woo, S., Lee, S.-J., Kim, D.-H., Kim, H., Kim, Y.: Conducting polymer/in situ generated platinum nanoparticle nanocomposite electrodes for low-cost dye-sensitized solar cells. Electrochim. Acta 116, 518-523 (2014). https://doi.org/10.1016/j.elect acta.2013.10.210

162. Hsiao, Y.-P., Su, W.-Y., Cheng, J.-R., Cheng, S.-H.: Electrochemical determination of cysteine based on conducting polymers/gold nanoparticles hybrid nanocomposites. Electrochim. Acta 56, 6887-6895 (2011). https://doi.org/10.1016/j.elect acta.2011.06.031

163. Koussi-Daoud, S., Schaming, D., Martin, P., Lacroix, J.-C.: Gold nanoparticles and poly(3,4-ethylenedioxythiophene) (PEDOT) hybrid films as counter-electrodes for enhanced efficiency in dyesensitized solar cells. Electrochim. Acta 125, 601-605 (2014). https://doi.org/10.1016/j.electacta.2014.01.154

164. Ghosh, S., Teillout, A.-L., Floresyona, D., de Oliveira, P., Hagège, A., Remita, H.: Conducting polymer-supported palladium nanoplates for applications in direct alcohol oxidation. Int. J. Hydrog. Energy. 40, 4951-4959 (2015). https://doi. org/10.1016/j.ijhydene.2015.01.101

165. Kim, K.-S., Kim, I.-J., Park, S.-J.: Influence of Ag doped graphene on electrochemical behaviors and specific capacitance of polypyrrole-based nanocomposites. Synth. Met. 160, 2355-2360 (2010). https://doi.org/10.1016/j.synthmet.2010.09.011

166. Hui, N., Wang, S., Xie, H., Xu, S., Niu, S., Luo, X.: Nickel nanoparticles modified conducting polymer composite of reduced graphene oxide doped poly(3,4-ethylenedioxythiophene) for enhanced nonenzymatic glucose sensing. Sens. Actuators B Chem. 221, 606-613 (2015). https://doi.org/10.1016/j. snb.2015.07.011

167. Lu, D., Zhang, Y., Wang, L., Lin, S., Wang, C., Chen, X.: Sensitive detection of acetaminophen based on $\mathrm{Fe}_{3} \mathrm{O}_{4}$ nanoparticlescoated poly(diallyldimethylammonium chloride)-functionalized graphene nanocomposite film. Talanta 88, 181-186 (2012). https ://doi.org/10.1016/j.talanta.2011.10.029

168. Ehsani, A., Jaleh, B., Nasrollahzadeh, M.: Electrochemical properties and electrocatalytic activity of conducting polymer/copper nanoparticles supported on reduced graphene oxide composite. J. Power Sources 257, 300-307 (2014). https://doi.org/10.1016/j. jpowsour.2014.02.010

169. Kalambate, P.K., Dar, R.A., Karna, S.P., Srivastava, A.K.: High performance supercapacitor based on graphene-silver nanoparticles-polypyrrole nanocomposite coated on glassy carbon electrode. J. Power Sources 276, 262-270 (2015). https:// doi.org/10.1016/j.jpowsour.2014.11.130

170. Sapurina, I., Stejskal, J.: Ternary composites of multi-wall carbon nanotubes, polyaniline, and noble-metal nanoparticles for potential applications in electrocatalysis. Chem. Pap. (2009). https:// doi.org/10.2478/s11696-009-0061-3

171. Heness, G.: Metal-polymer nanocomposites. (2012)

172. Li, Q., Mahmood, N., Zhu, J., Hou, Y., Sun, S.: Graphene and its composites with nanoparticles for electrochemical energy applications. Nano Today. 9, 668-683 (2014). https://doi. org/10.1016/j.nantod.2014.09.002

173. Roy, N., Sengupta, R., Bhowmick, A.K.: Modifications of carbon for polymer composites and nanocomposites. Prog. Polym. Sci. 37, 781-819 (2012). https://doi.org/10.1016/j.progpolyms ci.2012.02.002

174. Xue, K., Zhou, S., Shi, H., Feng, X., Xin, H., Song, W.: A novel amperometric glucose biosensor based on ternary gold nanoparticles/polypyrrole/reduced graphene oxide nanocomposite. Sens. Actuators B Chem. 203, 412-416 (2014). https://doi. org/10.1016/j.snb.2014.07.018

175. Jin, L., Gao, X., Wang, L., Wu, Q., Chen, Z., Lin, X.: Electrochemical activation of polyethyleneimine-wrapped carbon nanotubes/in situ formed gold nanoparticles functionalised nanocomposite sensor for high sensitive and selective determination of dopamine. J. Electroanal. Chem. 692, 1-8 (2013). https://doi. org/10.1016/j.jelechem.2012.12.021

176. Ruiyi, L., Qianfang, X., Zaijun, L., Xiulan, S., Junkang, L.: Electrochemical immunosensor for ultrasensitive detection of microcystin-LR based on graphene-gold nanocomposite/functional conducting polymer/gold nanoparticle/ionic liquid composite film with electrodeposition. Biosens. Bioelectron. 44, 235-240 (2013). https://doi.org/10.1016/j.bios.2013.01.007

177. Gholivand, M.B., Karimian, N.: Fabrication of a highly selective and sensitive voltammetric ganciclovir sensor based on electropolymerized molecularly imprinted polymer and gold nanoparticles on multiwall carbon nanotubes/glassy carbon electrode. Sens. Actuators B Chem. 215, 471-479 (2015). https://doi. org/10.1016/j.snb.2015.04.007

178. Zhang, C., Zhang, Y., Miao, Z., Ma, M., Du, X., Lin, J., Han, B., Takahashi, S., Anzai, J., Chen, Q.: Dual-function amperometric sensors based on poly(diallyldimethylammonium chloride)functionalized reduced graphene oxide/manganese dioxide/gold nanoparticles nanocomposite. Sens. Actuators B Chem. 222, 663-673 (2016). https://doi.org/10.1016/j.snb.2015.08.114

179. Lim, Y.S., Tan, Y.P., Lim, H.N., Huang, N.M., Tan, W.T., Yarmo, M.A., Yin, C.-Y.: Potentiostatically deposited polypyrrole/graphene decorated nano-manganese oxide ternary film for supercapacitors. Ceram. Int. 40, 3855-3864 (2014). https://doi. org/10.1016/j.ceramint.2013.08.026

Publisher's Note Springer Nature remains neutral with regard to jurisdictional claims in published maps and institutional affiliations. 